\title{
Hybrid Surrogate-Based Rubber Engine Model for Aircraft Multidisciplinary Design Optimization
}

\author{
J. Häßy*, J. Schmeink ${ }^{\dagger}$, R. Becker ${ }^{\ddagger}$, S. Reitenbach ${ }^{\S}$ and M. Vieweg ${ }^{\text {II }}$ \\ German Aerospace Center (DLR), Cologne, Germany, D-51147 \\ P. Bekemeyer" and A. Merle** \\ German Aerospace Center (DLR), Braunschweig, Germany, D-38108
}

\begin{abstract}
The engine design should be selected optimally in terms of the overall aircraft system taking into account snowball effects, since the engine size, weight and fuel consumption have a large influence on both the structural aircraft sizing process and the aerodynamics. But the Multidisciplinary Design Optimization (MDO) of an aircraft is a challenging task due to the high degree of coupling of various components and disciplines. Therefore, a scalable rubber engine model can be applied within the MDO to enable the optimal selection of an engine design while reducing additional complexity to a minimum. In this publication a hybrid surrogatebased rubber engine concept is proposed, which consists of surrogate-models covering a range of engine designs and a tool for thermodynamic cycle analysis. Thereby, dimensions, weight and center of gravity of different engine designs as well as the individual operating behaviour over the entire flight mission are made available for the MDO process. A generic three-spool unmixed turbofan design similar to the Trent 1000 is created. Design variations are performed to generate a rubber engine model that covers different thrust requirements and a range of bypass ratios. For the model creation, different methods for design of experiment and interpolation with a varying number of samples are assessed and compared.
\end{abstract}

\section{Nomenclature}

$\begin{array}{ll}A & =\text { flow area } \\ \mathrm{BPR} & =\text { bypass ratio } \\ C_{f} & =\text { weight calibration factor } \\ \mathrm{COG} & =\text { relative location of the center of gravity } \\ \mathrm{FN} & =\text { net thrust } \\ \mathrm{FN}_{\text {Ratio }} & =\text { ratio of maximum take-off to cruise thrust } \\ \mathrm{H} & =\text { flight altitude } \\ K_{v} & =\text { empirical blade volume factor } \\ \mathrm{L} & =\text { engine length } \\ N & =\text { rotational shaft speed } \\ \mathrm{OPR} & =\text { overall pressure ratio } \\ \mathrm{PR} & =\text { pitch ratio } \\ R_{m}^{\prime} & =\text { meanline radius ratio } \\ R_{t} & =\text { fan tip radius } \\ \mathrm{T}_{3} & =\text { outlet temperature of high pressure compressor } \\ \mathrm{T}_{4} & =\text { inlet temperature of high pressure turbine } \\ \mathrm{T}_{49} & =\text { inlet temperature of low pressure turbine } \\ & \end{array}$

\footnotetext{
*Research Associate, Institute of Propulsion Technology, Linder Hoehe, 51147 Cologne, Germany, jannik.haessy@ dlr.de

${ }^{\dagger}$ Research Associate, Institute of Propulsion Technology, Linder Hoehe, 51147 Cologne, Germany, jens.schmeink@dlr.de

†Team Leader, Institute of Propulsion Technology, Linder Hoehe, 51147 Cologne, Germany, richard.becker@ dlr.de

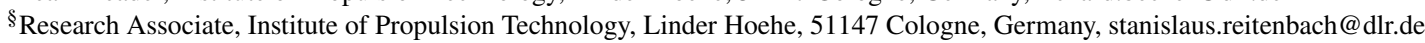

IIResearch Associate, Institute of Propulsion Technology, Linder Hoehe, 51147 Cologne, Germany, maximilian.vieweg@ dlr.de

" Team Leader, Aerodynamics and Flow Technology Institute, Lilienthalplatz 7, 38108 Braunschweig, Germany, philipp.bekemeyer@dlr.de

**Research Associate, Aerodynamics and Flow Technology Institute, Lilienthalplatz 7, 38108 Braunschweig, Germany, andrei.merle@dlr.de
} 


$\begin{array}{ll}\mathrm{TF} & =\text { trading factor to estimate changes in block fuel } \\ \mathrm{TSFC} & =\text { thrust specific fuel consumption } \\ U & =\text { circumferential velocity calculated with the area-averaged radius } \\ W & =\text { mass flow, bare engine weight } \\ W_{f} & =\text { fuel flow } \\ \mathrm{XM} & =\text { Mach number } \\ \Delta T_{\mathrm{ISA}} & =\text { temperature deviation from ISA } \\ \eta & =\text { polytropic efficiency, mechanical efficiency } \\ \Theta & =\text { cooling air mass flow related to high pressure compressor inlet mass flow } \\ v & =\text { hub-to-tip ratio } \\ \Pi_{\text {max,stage }} & =\text { maximum average stage loading }\end{array}$

\section{Introduction}

Complex dependencies exist between the engine and the aircraft during the design of the overall system. A schematic representation of an overall aircraft design process is shown in Fig. 1. Relevant flight missions are deduced from top level aircraft requirements (TLAR), e.g. passenger capacity (PAX), payload, range and transportation time. In order to develop an aircraft that fulfills these requirements, a numerous amount of design variables from various components and disciplines have to be set during an iterative process. This process could be either a collaborative stepwise design including different partners and departments or an automated process. Each aircraft component has its own set of requirements and design variables. For example, the engine has to deliver a certain thrust at various operating conditions and during the engine design, variables like the bypass ratio (BPR), the overall pressure ratio (OPR), the combustor outlet temperature $T_{4}$, the number of stages, the radial location of components and the rotational speed of shafts have to be selected. The geometry, weight, center of gravity and fuel consumption of the engine are set by defining all design variables. The fuel consumption influences the required tank volume, the dimensions of the engine affect the aircraft drag and the engine weight as well as its center of gravity the structural wing design. All aircraft components are integrated to build an overall aircraft system and the performance of this system is evaluated by means of relevant flight missions. The steps of integration and evaluation might lead to changed requirements for the aircraft components. The iterative design process is continued until all requirements are matched. Thereby, a well-working but not necessarily optimal aircraft is designed. The optimal adjustment of the design variables with regard to fuel burn, emissions, costs and noise of the overall system is a challenging task due to the high degree of coupling between the various disciplines and components. This task is addressed in the context of multidisciplinary design optimization (MDO) of an aircraft. Therefore, an automated process chain is combined with an optimization algorithm. Only the most important design variables of the aircraft components and disciplines are used for optimization to keep complexity limited. The component specific design processes are still in charge of defining many other degrees of freedom.

One option to integrate the engine design into a MDO process is the usage of a rubber engine model. This surrogate model is a scalable engine representation that provides engine designs for different requirements arising from the overall aircraft design (OAD). For example, when the thrust demand changes, the rubber engine model delivers a suitably sized engine that has been designed for the changed requirement. The purpose of this paper is to present a hybrid surrogate-based rubber engine concept. With this concept the dimensions, weight and center of gravity of the rubber engine as well as the detailed operating behaviour over the entire flight mission are made available for a MDO process. To demonstrate the proposed concept, the generation of a generic rubber engine model similar to the unmixed turbofan engine Trent 1000 is described. In a first step the model is designed to enable the optimal choice of engine size for minimizing the mission fuel burn of the overall system. To create a rubber engine model for this purpose, it is necessary to design engines of different size taking into account varying requirements, e.g. thrust demands or diameter limitations coming from OAD. Thermodynamic cycle analysis and conceptual design methods to determine geometry and weight are applied for the engine design. Furthermore, it is investigated with which meta-modeling techniques a rubber engine model can be build most efficiently and what accuracy can be expected when applying the rubber engine model. Therefore, different design of experiment (DoE) and interpolation methods with a varying number of samples are assessed. The presented work was created in the context of the project VicToria (Virtual Aircraft Technology Integration Platform) at the German Aerospace Center (DLR). 


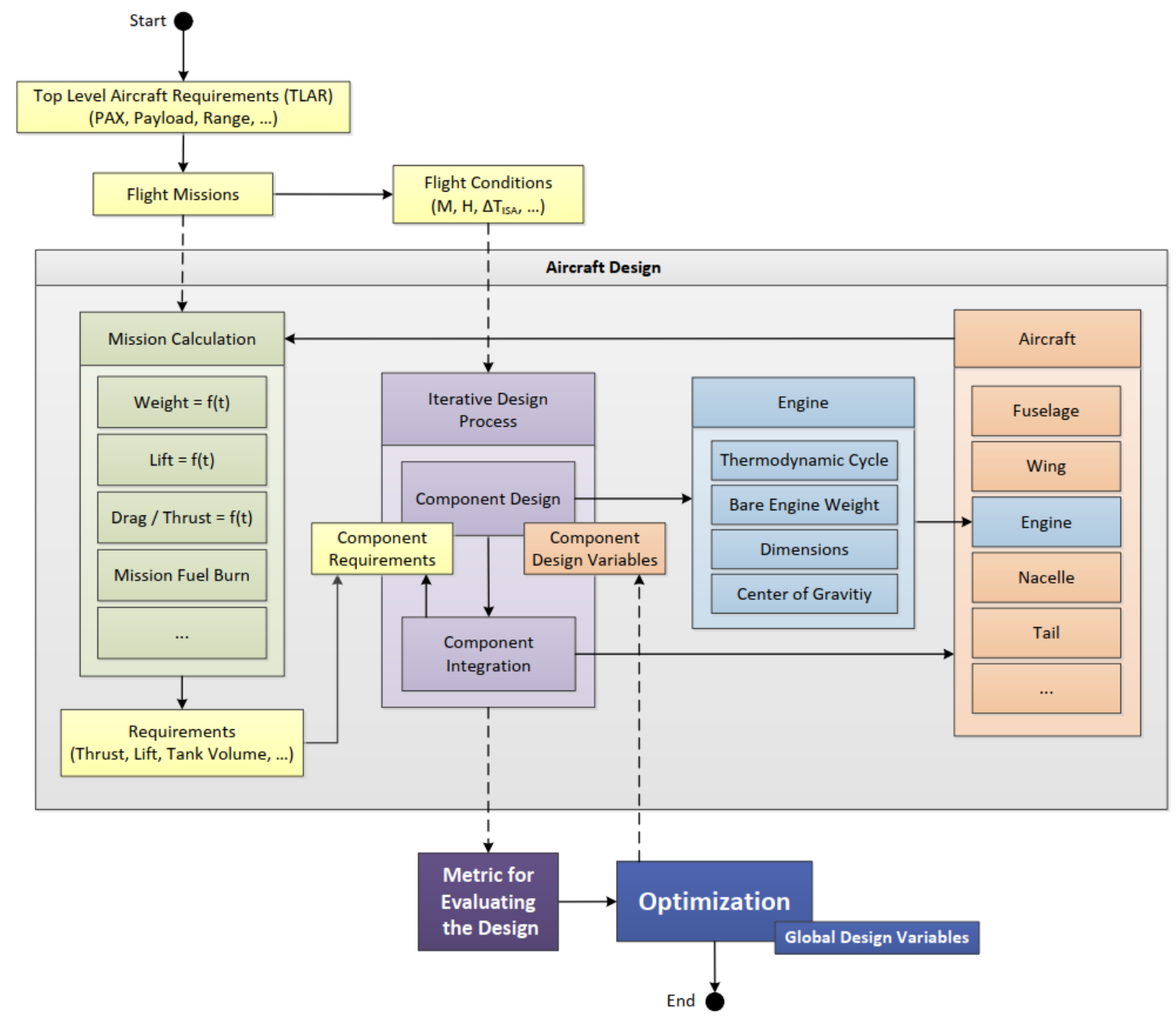

Fig. 1 Qualitative visualization of an overall aircraft design process.

\section{State of the Art}

A large part of published MDO studies in the context of aircraft design focuses on aerostructural optimization problems with a particular interest in employing high-fidelity methods like RANS and FEM [1-4]. Extending the MDO design space by engine design variables is a promising idea, since the engine sizing has a large influence on both the structural sizing process, e.g. an increase in engine weight leads to higher loads, and on the aerodynamics, e.g. the variation of the outer engine diameter strongly affects the installation drag. Along these lines, stepwise progress has been made in the field of aerodynamic or aeroelastic high-fidelity shape optimization with powered engines [5-7]. In this context, coupled engine models for thermodynamic cycle analysis provide the CFD boundary conditions for requested thrust values. Moreover, current work of the authors [1] accounts for this kind of RANS-based aeropropulsive coupling in a large scale MDO process, which includes also disciplines like OAD, structural sizing based on a comprehensive loads process and aeroelastic stability. The engine sizing is planned to be included in near future in this MDO by taking into account major cross-disciplinary effects - the ones described before, but also potential snowball effects resulting from interactions with OAD or sensitive responses of flutter stability due to varying engine weight.

In the field of rubber engine models some work has already been done. Raymer presented a methodology for rubber engine sizing during aircraft design and provided scaling laws for the weight, dimensions and fuel consumption of piston and turboprop engines [8]. Drela developed a MDO framework for aircraft preliminary design in which a basic component-based performance program is used to model the thermodynamic cycle of engines [9]. This framework was 
later extended by surrogate-based weight models for direct-drive and geared turbofan engines, which are evaluated by means of thermodynamic cycle parameters [10, 11]. Kupijai presented an automated multidisciplinary process for engine preliminary design and generated a data set that contains engine designs for a range of parameters [12]. These parameters include the thrust at different operating conditions, the fan diameter as well as characteristic cycle temperatures at maximum take-off (MTO). Based on this data set, surrogate models were build that describe the weight and operational behaviour of the engine at predefined conditions in dependence on the mentioned parameters [13]. The hybrid surrogate-based rubber engine concept that is proposed in this publication combines the direct coupling of a performance tool with the approach of describing the engine design via surrogate models. Thereby, the performance of the engine can be evaluated not only at predefined conditions but also over the entire flight mission, whereby a detailed overview of the engine performance is provided for each operating point.

\section{Hybrid Surrogate-based Rubber Engine Concept}

The concept of the proposed hybrid surrogate-based rubber engine model includes a set of surrogate-models and the incorporation of a thermodynamic performance tool (see Fig. 2). The surrogate models contain information on parameters from different disciplines whereas the performance program enables the evaluation of the engine operating behaviour over the entire flight mission. This combination results in the hybrid character of the approach. The surrogate models provide engine parameters for each design, eg. length, radii, areas, bare engine weight and center of gravity. Furthermore, all variables that uniquely define the thermodynamic cycle of each engine at the design operating point are covered. This includes pressure ratios of the compressors, component efficiencies, the engine mass flow, the fuel-to-air ratio of the combustor and the rotational speed of shafts. These thermodynamic characteristics are transferred within the hybrid rubber engine model to a coupled tool for thermodynamic cycle calculation. The operating behaviour of the engine can then be calculated at any operating point given by a set of flight conditions and an engine power parameter. Due to the ability to calculate off-design performance, this approach minimizes the amount of data that must be provided via surrogate models. The rubber engine model is build for a previously defined parameter space delivering an engine design for each parameter combination. The model parameters selected for the rubber engine model should include main design variables and requirements that cover the most important coupling influences between the aircraft and the engine. For example, model parameters could be the required thrust at sizing operating conditions, the design flight Mach number or the engine diameter. All further degrees of freedom, which are not part of the model parameters, have to be defined during the engine design, preferably optimal in terms of the overall aircraft system. During the aircraft MDO, the model parameters of the rubber engine can be varied to adapt the engine design according to requirements arising from $\mathrm{OAD}$ and to find the optimal engine design parameters in terms of the overall aircraft system.

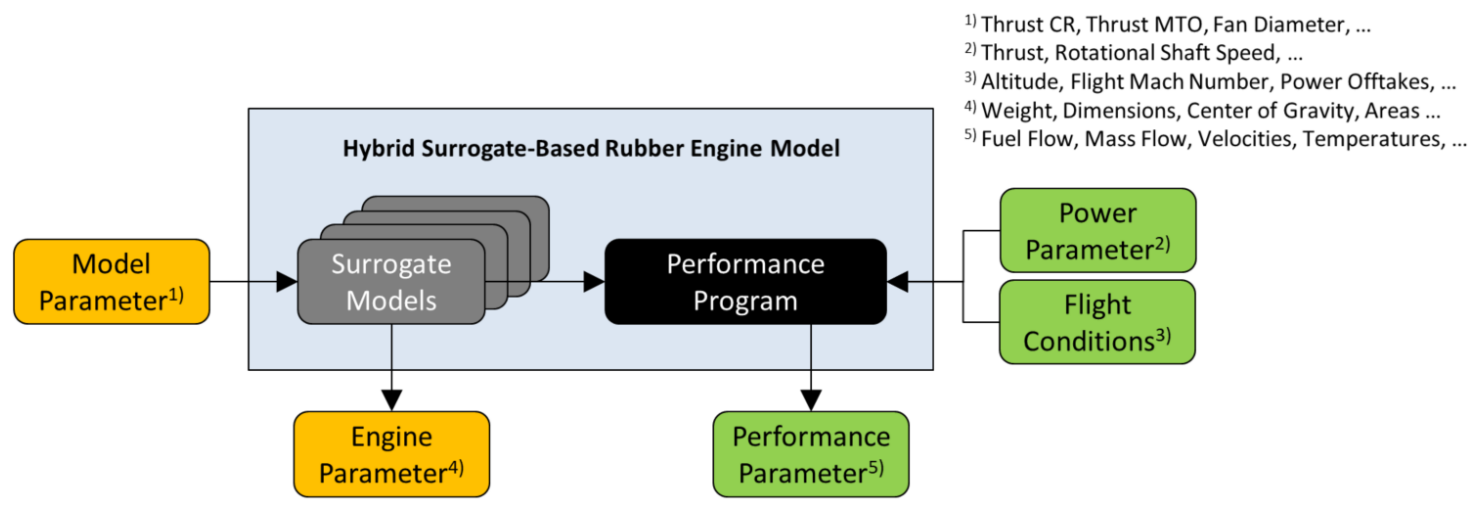

Fig. 2 Concept of the hybrid surrogate-based rubber engine model.

All functionalities of the applied performance tool are available. In addition to global engine parameters such as the thrust specific fuel consumption (TSFC), detailed information on the thermodynamic state of the fluid at individual engine stations can be calculated. For example, information on pressures and temperatures may become necessary as boundary conditions in order to couple the model with CFD calculations of the aircraft [5].

Compared to integrating the design process chain directly, the use of a surrogate-based rubber engine model for MDO applications offers the advantage that the complex engine design is encapsulated as a preprocessing step, thus 
reducing the complexity of the MDO process and increasing its robustness. But this requires sufficient knowledge of the parameter range that has to be covered by the model at the time of model creation. In addition, the model can be reviewed by an engine expert increasing the validity of results. Furthermore, the rubber engine model facilitates the exchange with other organizations or departments, since only common tools for meta-modeling and thermodynamic calculation are required and not all tools, models and process chains must be shared. The selected tool for thermodynamic cycle analysis is principally exchangeable with little effort. The usage of surrogate-models enables multi-fidelity approaches and the uncomplicated determination of derivatives and sensitivities. Discontinuous changes induced by the discrete transition of integer-numbered parameters like the stage number are transformed into continuous problems via the surrogate-models, which will be discussed in section VIII.

\section{Tools}

For the engine design, the virtual engine platform Gas Turbine Laboratory (GTlab) [14, 15] is used, which is developed at the Institute of Propulsion Technology of the DLR. In addition to an extensive process management environment and a central data model for data exchange, a broad collection of methods and coupled tools for engine design and analysis is available. For thermodynamic cycle calculations, the DLR Performance Program (DLRp2) [16] coupled to the performance interface of GTlab is applied. The flight mission analysis to determine required thrusts for different operating conditions and trading factors is performed with Piano-X. The software Surrogate Modeling for AeRo Data Toolbox in python (SMARTy), which is developed primarily at the Institute of Aerodynamic and Flow Technology of the DLR, provides surrogate modeling capabilities for complex aerospace workflows [17-19]. It is designed as an application programming interface (API) giving easy access to the underlying modules. SMARTy provides methods for design of experiment, dimensionality reduction, reduced order modeling, model selection and various other data-driven modeling tasks.

\section{Engine Design Methodology}

In order to create the required data for the rubber engine model, engine designs must be generated for different combinations of model parameters. Therefore, a process chain to design the thermodynamic cycle and to estimate engine geometry and weight becomes necessary. In order to design physically reasonable and comparable engines, the major dependencies of the engine components as well as restricting constraints must be taken into account and a constant technological level has to be maintained. Based on the applied conceptual design methods described in the following subsections, no detailed design with high quantitative precision can be expected. The aim is to generate physically reliable trends when main engine design variables are changed and on this basis to derive correct design decisions. The calibration of the conceptual design methods utilizing a well-known reference increases the quantitative precision of investigations.

\section{A. Reference Engine Model}

In the context of conceptual and preliminary design it is common practice to select a realistic well-known engine as reference, which serves as a starting point for further investigations. This reference can be used to calibrate the applied design methods in order to reduce systematic errors and to increase the validity of results [20]. In this publication, a generic model of a three-shaft unmixed turbofan engine similar to the Trent 1000 is selected as reference. Data for the Trent 1000, which has been designed to power the Boeing 787 family, is taken from public sources [21-23]. The high bypass ratio Trent 1000 engine has a single stage low hub-to-tip ratio fan with a diameter of $2.85 \mathrm{~m}$ powered by a six stage axial-flow low pressure turbine. Both the intermediate and high pressure systems consist of an axial-flow compressor with eight respectively six stages and a single stage turbine, each connected to the corresponding compressor by counter-rotating coaxial shafts. Different versions of the Trent 1000 engine are certified, which differ mainly in the technology package and thrust rating. The Trent 1000-R3 incorporates the latest technology upgrade with the package TEN and is certified for the highest static thrust. The reference engine model is build based on available data for this Trent 1000 version. In addition to the thermodynamic cycle and the estimation of the geometry, the weight is also determined. Missing thrust requirements are calculated, unknown thermodynamic parameters are estimated using statistical methods according to [24] and geometric parameters are extracted from a cross-sectional drawing published in [25]. Starting from this baseline model, parameter variations are made to generate the designs required for the rubber engine model. In the following subsections, the applied design methods for the disciplines thermodynamics, geometry and weight are briefly described, accompanied by selected data from the reference engine model. 


\section{B. Reference Aircraft Model}

A generic aircraft model similar to the Boeing 787-8 is considered to calculate thrust requirements for the operating conditions cruise (CR) and top of climb (TOC). Table 1 shows an overview of the aircraft model and flight missions calculated with Piano-X. The aircraft weight and capacity parameters are taken from [26]. According to the manufacturer specification , the design mission with a maximum range of $13620 \mathrm{~km}$ is performed with 242 passengers. The achieved maximum range of the aircraft model with the assumption of $102 \mathrm{~kg}$ per PAX is with $13841 \mathrm{~km}$ in good agreement. Besides the design mission, a typical mission is considered. Therefore, a combination of range and payload is selected that is often flown based on data for Boeing 787-8 flights analyzed in [27]. Trading factors $\mathrm{TF}_{i}$ to take into account the impact of changes in TSFC and engine weight on block fuel are calculated for this typical mission and will be applied during the design study described later.

Table 1 Overview of reference aircraft parameters and flight missions calculated with Piano-X.

\begin{tabular}{|lc|c||lc|cc|}
\hline Parameter & Unit & B787-8 Model & Parameter & Unit & Design Mission & Typical Mission \\
\hline \hline $\begin{array}{l}\text { Max. Take-off } \\
\text { Weight }\end{array}$ & {$[\mathrm{kg}]$} & 227930 & Range & {$[\mathrm{km}]$} & 13841 & 8000 \\
\hline $\begin{array}{l}\text { Operating } \\
\text { Empty Weight }\end{array}$ & {$[\mathrm{kg}]$} & 119950 & Payload & {$[\mathrm{kg}]$} & 24684 & 30000 \\
\hline $\begin{array}{l}\text { Fuel } \\
\text { Capacity }\end{array}$ & {$[1]$} & 126206 & Block Fuel & {$[\mathrm{kg}]$} & 76265 & 42547 \\
\hline $\begin{array}{l}\text { Max. Zero } \\
\text { Fuel Weight }\end{array}$ & {$[\mathrm{kg}]$} & 161100 & $\mathrm{TF}_{\mathrm{TSFC}}$ & {$[\% \mathrm{FB} / \% \mathrm{TSFC}]$} & - & 1.130 \\
\hline $\begin{array}{l}\text { Max. Landing } \\
\text { Weight }\end{array}$ & {$[\mathrm{kg}]$} & 172365 & $\mathrm{TF}_{W}$ & {$[\% \mathrm{FB} / \mathrm{t}]$} & - & 0.582 \\
\hline
\end{tabular}

\section{Thermodynamic Cycle Design}

The thermodynamic cycle schematic for a generic three-spool unmixed turbofan engine using the modular component-based approach provided by the GTlab framework is shown in Fig. 3 The design of the thermodynamic cycle is made within an iterative process taking into account the operating conditions CR, MTO on a hot day as well as on a ISA standard day. The off-design behaviour of the turbo components is modeled by means of generic component maps, which are scaled for the $\mathrm{CR}$ condition. In the following, the procedure for modeling the reference engine utilizing available data regarding the Trent 1000 is described. An overview of the reference thermodynamic cycle characteristics for the operating conditions CR, TOC and hot day MTO is given in Tab. 2

The thrust requirement for the Trent 1000-R3 at sea-level static (SLS) MTO is taken from the EASA type certificate data sheet [21]. The flight conditions and the thrust demands for TOC and CR come from the flight mission calculation for the design range, whereby for CR the conditions at half cruise distance are considered. Although the reference aircraft model, similar to the Boeing 787-8, does not need the high MTO thrust, the highest MTO thrust is selected for the thermodynamic model to take into account that the engine has to be designed for an aircraft family. The ICAO engine emissions database provides information on the performance of certified Trent 1000 engines for different SLS thrusts at standard day conditions [22]. This includes values for the BPR and OPR at MTO. The reference thermodynamic cycle is adjusted to match these values at the corresponding operating condition. The shaft speeds are set according to the maximum permissible values given in [21] at the hot day MTO condition.

The cooling air for the high pressure turbine (HPT) is extracted from the exit of the high pressure compressor (HPC). For the intermediate pressure turbine (IPT), it is taken from a position in the middle of the compressor assuming a relative enthalpy of $60 \%$. The cooling air demands are determined by a statistical correlation presented in [24] assuming a high technological level. The stator outlet temperature of the single-stage turbines as well as the temperature of the corresponding cooling air are taken into account to estimate the required cooling air mass flow. For both turbines

*https://www.boeing.com/commercial/787/by-design/\#/787-8-characteristics, accessed 14.01.2020 


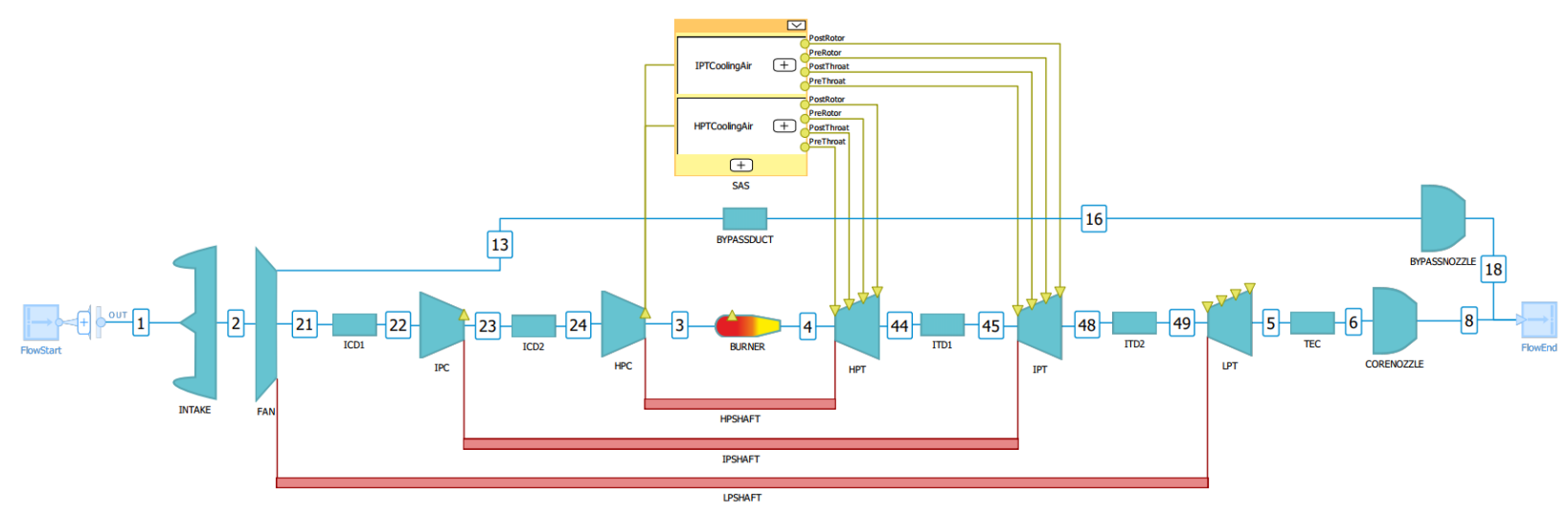

Fig. 3 Thermodynamic cycle schematic of a generic three-spool unmixed turbofan engine in GTlab.

Table 2 Thermodynamic cycle characteristics of the reference engine model for selected operating conditions.

\begin{tabular}{|lc|ccc||lc|ccc|}
\hline Parameter & Unit & CR & TOC & MTO & Parameter & Unit & CR & TOC & MTO \\
\hline \hline $\mathrm{H}$ & {$[\mathrm{m}]$} & 11887 & 10668 & 0 & $\Pi_{\text {Intake }}$ & {$[-]$} & 0.996 & 0.996 & 0.996 \\
$\mathrm{XM}$ & {$[-]$} & 0.85 & 0.819 & 0 & $\Pi_{\text {FAN }}$ & {$[-]$} & 1.532 & 1.613 & 1.604 \\
$\Delta T_{\text {ISA }}$ & {$[\mathrm{K}]$} & 0 & 0 & 15 & $\Pi_{\text {BD }}$ & {$[-]$} & 0.982 & 0.982 & 0.983 \\
$W_{\text {Intake }}$ & {$[\mathrm{kg} / \mathrm{s}]$} & 407.7 & 502.7 & 1209.7 & $\Pi_{\text {ICD1 }}$ & {$[-]$} & 0.995 & 0.994 & 0.994 \\
FN & {$[\mathrm{kN}]$} & 44.31 & 64.58 & 363.9 & $\Pi_{\text {IPC }}$ & {$[-]$} & 6.784 & 7.234 & 7.137 \\
OPR & {$[-]$} & 43.1 & 49.8 & 49.4 & $\Pi_{\text {ICD2 }}$ & {$[-]$} & 0.995 & 0.995 & 0.995 \\
BPR & {$[-]$} & 9.75 & 9.08 & 8.86 & $\Pi_{\text {HPC }}$ & {$[-]$} & 4.203 & 4.334 & 4.382 \\
$\mathrm{~T}_{3}$ & {$[\mathrm{~K}]$} & 793.6 & 829.0 & 989.3 & $\Pi_{\text {Combustor }}$ & {$[-]$} & 0.95 & 0.95 & 0.95 \\
$\mathrm{~T}_{4}$ & {$[\mathrm{~K}]$} & 1517.2 & 1610.9 & 1932.2 & $\Pi_{\text {HPT }}$ & {$[-]$} & 2.631 & 2.630 & 2.622 \\
TSFC & {$[\mathrm{g} / \mathrm{kNs}]$} & 14.21 & 14.11 & 7.92 & $\Pi_{\text {IPT }}$ & {$[-]$} & 2.372 & 2.366 & 2.338 \\
$W_{f}$ & {$[\mathrm{~kg} / \mathrm{s}]$} & 0.629 & 0.911 & 2.883 & $\Pi_{\text {LPT }}$ & {$[-]$} & 6.218 & 6.262 & 5.562 \\
$\eta_{\text {FAN }}$ & {$[-]$} & 0.932 & 0.922 & 0.928 & $\Pi_{\text {TEC }}$ & {$[-]$} & 0.985 & 0.985 & 0.988 \\
$\eta_{\text {IPC }}$ & {$[-]$} & 0.906 & 0.906 & 0.905 & $N_{\text {HPSHAFT }}$ & {$[1 / \mathrm{s}]$} & 199.5 & 205.6 & 226.5 \\
$\eta_{\text {HPC }}$ & {$[-]$} & 0.896 & 0.896 & 0.895 & $N_{\text {IPSHAFT }}$ & {$[1 / \mathrm{s}]$} & 136.3 & 139.8 & 154.2 \\
$\eta_{\text {Combustor }}$ & {$[-]$} & 0.999 & 0.999 & 0.999 & $N_{\text {LPSHAFT }}$ & {$[1 / \mathrm{s}]$} & 39.7 & 42.1 & 45.4 \\
$\eta_{\text {IPT }}$ & {$[-]$} & 0.923 & 0.923 & 0.924 & $\eta_{\text {HPSHAFT }}$ & {$[-]$} & 0.998 & 0.998 & 0.998 \\
$\eta_{\text {HPT }}$ & {$[-]$} & 0.888 & 0.888 & 0.889 & $\eta_{\text {LPSHAFT }}$ & {$[-]$} & 0.998 & 0.998 & 0.998 \\
$\eta_{\text {LPT }}$ & {$[-]$} & 0.935 & 0.933 & 0.932 & $\eta_{\text {IPSHAFT }}$ & {$[-]$} & 0.996 & 0.996 & 0.996 \\
$\Theta_{\text {HPT }}$ & {$[-]$} & 0.1611 & 0.1611 & 0.1611 & $A_{\text {CN }}$ & {$\left[m^{2}\right]$} & 0.724 & 0.724 & 0.724 \\
$\Theta_{\text {IPT }}$ & {$[-]$} & 0.0624 & 0.0624 & 0.0624 & $A_{B N}$ & {$\left[m^{2}\right]$} & 3.255 & 3.255 & 3.255 \\
\hline
\end{tabular}

the assumption is made that $70 \%$ of the cooling air takes part in the conversion of energy. The relative shares $\Theta_{i}$ of the cooling air mass flows in relation to the HPC inlet mass flow are assumed to be constant for all operating conditions. The LPT is modeled as an uncooled turbine.

The pressure ratio of the fan is calculated by the condition of an ideal nozzle velocity ratio for unmixed turbofan engines. This condition states that the jet velocity ratio of the bypass $(\mathrm{BN})$ to the core nozzle $(\mathrm{CN})$ has to be equal to the 
transmission efficiency of the low pressure system. Thereby, an optimal split between the thrust generation of the bypass and core nozzle can be achieved, which leads to a minimal fuel consumption. Moreover, an equal mean stage pressure ratio is assumed for both the HPC and IPC. In combination with the given stage numbers of the Trent 1000, the pressure split between the intermediate and high pressure system is defined. The pressure losses in the intake as well as in the bypass duct (BD) and the turbine exhaust casing (TEC), which include all friction up to the nozzles, are set according to CFD calculations of a comparable engine including nacelle [5]. The pressure losses in the ducts between compressors (ICD) are estimated on the basis of empirical values given in [28] and the friction in the ducts that connect turbines is neglected due to their short length.

The polytropic efficiency of turbo components is estimated by means of statistical correlations given in [24]. The fan inlet Mach number is fixed to 0.61 at CR to ensure a sufficient margin of the flow capacity for TOC and avoid choking of the fan. In total, the thermodynamic cycle of the reference engine is uniquely defined by this set of prescribed values, restrictions, assumptions and applied models.

In Fig. 4 the reference engine model is compared to available performance data [22] on all Trent 1000 versions that have exactly the same diameter, length and weight [21]. These versions are assumed to be identical in construction but certified for different thrust ratings. Figure 4a depicts the BPR over the SLS thrust. The BPR values provided in the ICAO database are rounded to the first decimal digit. Therefore, a slightly lower value for the BPR compared to the R3 version has been selected following the decreasing trend of the ICAO data points. The maximum deviation in BPR with approximately $1.3 \%$ occurs at a MTO rating with low thrust. The comparison of the OPR in Fig. 4b shows good agreement between the ICAO data and the reference engine model for different SLS thrusts. The same applies to the TSFC at the high load points take-off and climb out (Fig. 4c). At the part load points approach and idle the reference engine model underestimates the TSFC but the qualitative trend at low thrusts is predicted correctly. The absolute fuel flow as a function of SLS thrust is shown in Fig. 4d to point out that the largest deviations in TSFC occur at operating conditions with low fuel consumption. In addition to the ICAO data, further information on the Trent 1000 published in [23], which has not been considered so far, is used to cross check the thermodynamic cycle of the reference engine model. An engine mass flow up to $1211 \mathrm{~kg} / \mathrm{s}$ and an OPR of 50 at climb are specified, which is consistent with the created model (see Tab. 2). Furthermore, the TSFC for cruise is given with $14.325 \mathrm{~g} / \mathrm{kNs}$, but no data for the corresponding flight conditions or thrust are available. Nonetheless, this value is in the same range as the model prediction with TSFC $=14.21 \mathrm{~g} / \mathrm{kNs}$. The statement about a BPR of 10.7 at cruise can not be confirmed, since a value of 9.75 is determined. Overall it can be concluded that the reference engine model is well calibrated against the available data on the Trent 1000 engine, apart from small deviations in the BPR.

Starting from this baseline thermodynamic cycle, parameter variations are performed to create the engine designs for the rubber engine model. When parameters are varied different physical effects and dependencies between the engine components have to be considered by the application of design laws to ensure feasible engine designs. In order to maintain a constant technology level within the thermodynamic cycle design, temperature limits which determine the maximum permissible thermal load are specified in Tab. 3. For the outlet temperature of the HPC $\mathrm{T}_{3}$ and the inlet temperature of the HPT $\mathrm{T}_{4}$ the maximum values of the reference thermodynamic cycle, which occur at hot day MTO, are selected as limits, since it is assumed that the reference engine design is pushed to the possible temperature limits for currently available technology. Furthermore, the inlet temperature of the low pressure turbine (LPT) $\mathrm{T}_{49}$ is restricted to allow an uncooled turbine concept.

Table 3 Constraints for thermodynamic cycle design.

\begin{tabular}{|lcc|}
\hline Parameter & Unit & Restriction \\
\hline \hline$T_{3}$ & {$[\mathrm{~K}]$} & $\leq 989$ \\
$T_{4}$ & {$[\mathrm{~K}]$} & $\leq 1932$ \\
$T_{49}$ & {$[\mathrm{~K}]$} & $\leq 1270$ \\
\hline
\end{tabular}

The cooling air demand is determined with the same method as for the reference engine by considering the turbine stator outlet temperature and the cooling air temperature at hot day MTO. The location of cooling air extraction and the split of working to non-working cooling air mass flow remains unchanged for all designs. The influence of the component size on its efficiency is taken into account by applying statistical correlations according to [24], e.g. smaller 


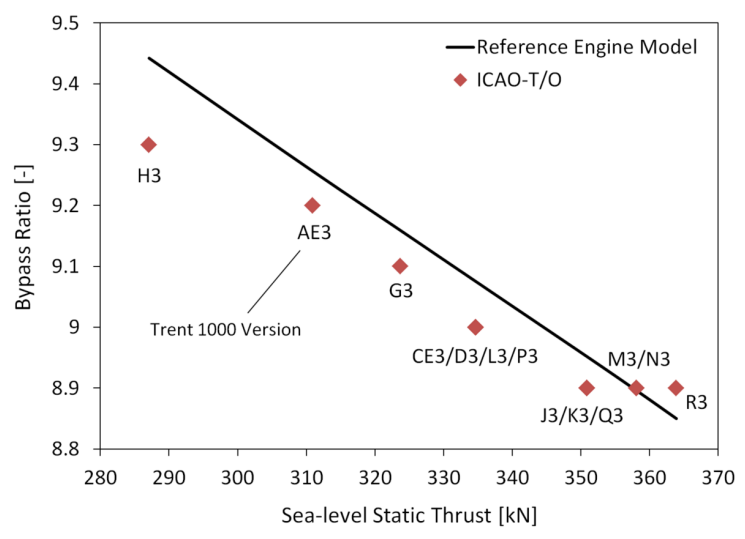

(a) Bypass ratio

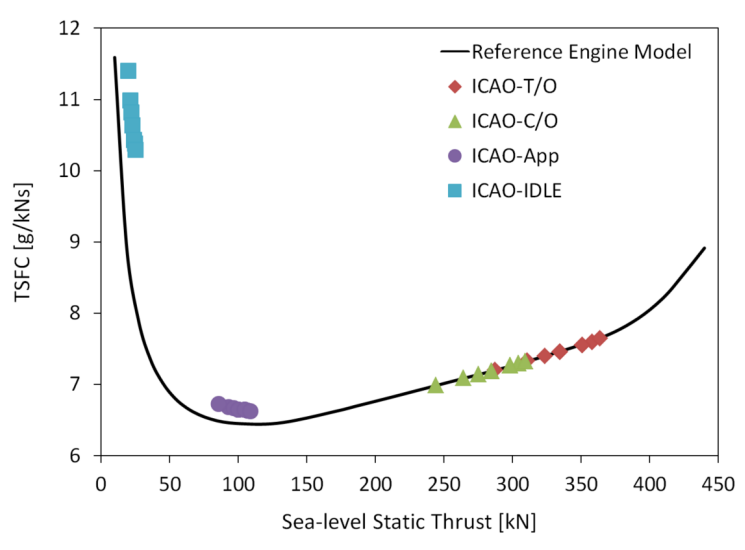

(c) Thrust specific fuel consumption

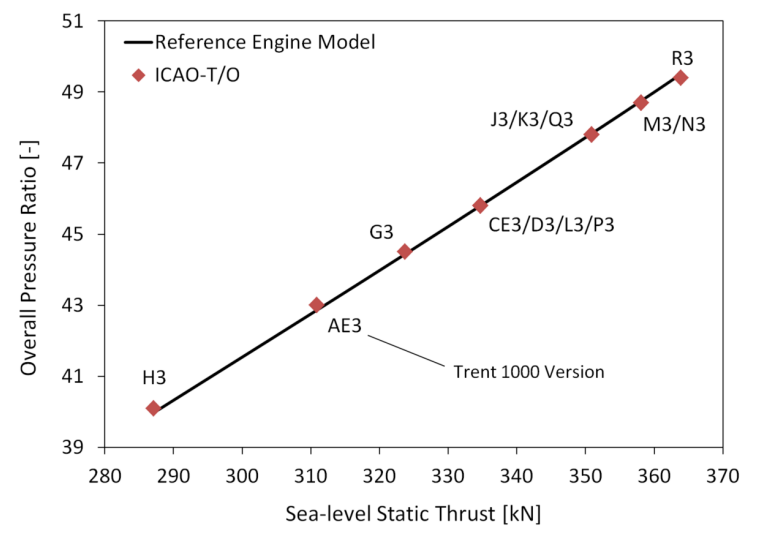

(b) Overall pressure ratio

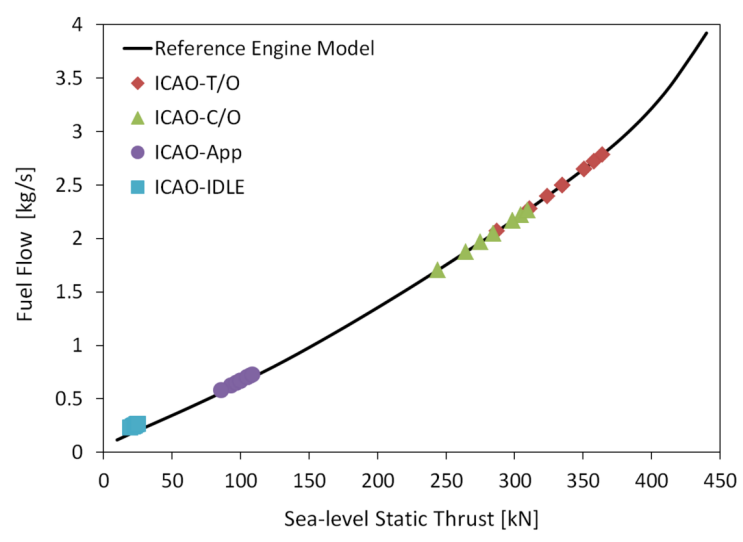

(d) Fuel flow

Fig. 4 Thermodynamic performance parameter of the reference engine model compared to available data on certified Trent 1000 versions [22] with varying SLS thurst. The different ICAO thrust definitions take-off (T/O), climb out (C/O), approach (App) and idle (IDLE) are considered.

turbo components lead to higher gap losses. The baseline efficiency of the reference model is therefore corrected based on the actual reduced mass flow through the component. The impact of the stage loading on the efficiency is neglected, which is acceptable as the number of stages will be set in order to keep the stage loading in a similar range. The influence of the cooling air mass flow on the turbine efficiency is accounted for by an empirical model presented in [24]. The fan efficiency is modeled in dependence on the fan pressure ratio, which is calculated to fulfill the condition for the optimum jet velocity ratio for unmixed turbofan engines. In addition the pressure split between the intermediate and high pressure system is kept constant. This ensures a balanced load distribution on the turbines, which should only have a single stage. Pressure losses in ducts are assumed to be constant for all designs.

\section{Geometry Estimation}

The geometry of the engine annulus is estimated by means of thermodynamic cycle data and mostly dimensionless geometrical parameters in a knowledge-based process. The mentioned geometrical parameters are taken from a general arrangement (GA) similar to the Trent 1000 engine published in [25] and form the knowledge-base for geometry estimation. Therefore, the GA is slightly scaled by a factor of 0.93 in the axial direction to match the specified length of the Trent 1000-R3 given in [21]. The knowledge base includes curves for the meanline and the annulus height in a normalized form and parameterized by B-splines for all components. In addition, the axial aspect ratio, axial taper ratio, leading edge angle, pitch ratio PR and blade gap length for the individual blade rows of the turbo components as well as information on the radial position of components are covered. 
Table 4 Selected data of the knowledge-base for geometry and weight modeling.

\begin{tabular}{|c|c|c|c|c|c|c|c|c|}
\hline Parameter & Unit & FAN & IPC & HPC & HPT & IPT & LPT & TEC \\
\hline $\mathrm{XM}_{\mathrm{in}}$ & {$[-]$} & 0.610 & 0.406 & 0.469 & 0.106 & 0.284 & 0.383 & - \\
\hline $\mathrm{XM}_{\text {out }}$ & {$[-]$} & $0.377 / 0.460^{1}$ & 0.297 & 0.203 & 0.322 & 0.396 & 0.433 & 0.474 \\
\hline$v_{\text {in }}$ & {$[-]$} & 0.257 & 0.630 & 0.816 & 0.824 & 0.865 & 0.855 & - \\
\hline$v_{\text {out }}$ & {$[-]$} & - & - & - & - & 0.853 & 0.723 & 0.717 \\
\hline$R_{\mathrm{m}}^{\prime}$ & {$[-]$} & - & 0.882 & 1.036 & 1.040 & - & - & - \\
\hline $\mathrm{PR}_{\text {Rotor }}$ & {$[-]$} & 0.80 & 0.96 & 0.91 & 1.21 & 1.21 & 0.69 & - \\
\hline $\mathrm{PR}_{\text {Stator }}$ & {$[-]$} & 1.00 & 0.79 & 0.79 & 1.31 & 1.31 & 1.09 & - \\
\hline$U_{\text {in }}$ & {$[\mathrm{m} / \mathrm{s}]$} & - & 412.4 & 377.0 & - & - & - & - \\
\hline $\bar{\psi}_{\text {max,stage }}$ & {$[-]$} & - & 0.55 & 0.9 & 4.4 & 3.5 & 4.4 & - \\
\hline$K_{\mathrm{v}, \text { Rotor }}$ & {$[-]$} & 0.055 & 0.06 & 0.12 & 0.195 & 0.195 & 0.045 & - \\
\hline$K_{\mathrm{v}, \text { Stator }}$ & {$[-]$} & 0.055 & 0.06 & 0.12 & 0.195 & 0.195 & 0.045 & - \\
\hline Material & & \multicolumn{2}{|c|}{ Titanium } & \multicolumn{4}{|c|}{ Nickel-based Alloy } & Titanium \\
\hline
\end{tabular}

The flow areas at the inlet and outlet station of components are estimated by means of Mach number assumptions in combination with the thermodynamic state of the fluid that comes from the performance calculation. The Mach numbers for the reference engine model are determined by matching the flow areas extracted from the GA for the CR condition and can be found in Tab. 4. This set of Mach numbers will be applied to all further engine designs.

The hub, tip and mean radii of an annulus station can be calculated by specifying a hub-to-tip ratio $v$ and using the flow area. If either the mean radius at the inlet or outlet of a component is available, the other one can be set by a prescribed mean radius ratio $R_{\mathrm{m}}^{\prime}$. The assumption of a constant $v$ for core components is justified as long as the core engine is only slightly changed in relation to the reference. At the fan inlet $v$ is usually chosen as small as possible to increase the flow capacity of the fan. If the BPR is changed compared to the reference, the assumption of a constant $v$ at the outlet of the bypass and core section leads to infeasible geometries. For this reason, the radial position at the fan outlets is calculated based on a constant tip radius ratio of the outer fan contour and a consideration of the flow areas as well as the adjacent component to the core outlet. The values for $v$ and $R_{\mathrm{m}}^{\prime}$ for the reference engine model come from the GA, are summarized for specific locations in Table 4 and will be maintained for all engine designs. The assumed $v$ at the fan inlet is extremely low but is in line with a statement about the Trent 1000 in [23]. For the outlet of the HPC, IPC and HPT, $R_{\mathrm{m}}^{\prime}$ is specified. When pressure ratios are varied, this leads to component geometries in accordance with conventional designs rather than a constant $v$.

The rotational speed of the intermediate and high pressure shaft is adjusted to keep a constant circumferential velocity $U_{\text {in }}$ at the inlet of the compressors at MTO on a standard day, whereby $U_{\text {in }}$ is calculated by the area-averaged radius. The used values for $U_{\text {in }}$ are estimated on the basis of the rotational speeds of the reference engine model and can be found in Tab. 4. The rotational speed of the low pressure shaft is determined by the reduced circumferential speed at the fan tip, which is modeled as a function of the fan pressure ratio according to [24]. The thermodynamic cycle data, the shaft speeds and a prescribed maximum permissible average stage loading $\bar{\psi}_{\text {max,stage }}$ at CR (see Tab. 4 lead to a required number of stages for the turbo components. The maximum values for the stage loading are selected considering the statistical correlations from [24] and the procedure results in stage number estimates equal to the Trent 1000 engine.

The two-dimensional annulus of a component, apart from the axial dimensions, is defined by the mean radii and the flow areas at the inlet and outlet as well as the normalized curves for the meanline and the annulus height. The geometry of a blade in this annulus is uniquely defined by the aspect ratio, taper ratio, leading edge angle and blade gap size, whereby linear leading and trailing edges are assumed. By drawing the blades according to the blade parameters and the number of stages, the axial positions and the total component length can be determined in an iterative process, which leads to a two-dimensional geometry of the component. The blade parameters are taken from the knowledge base. If 


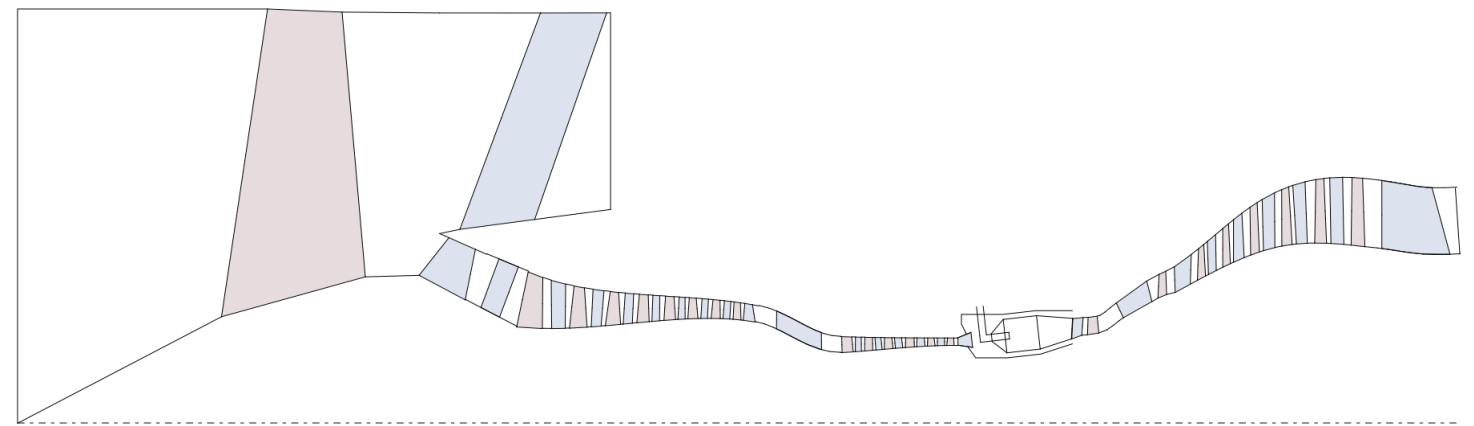

(a) Engine annulus

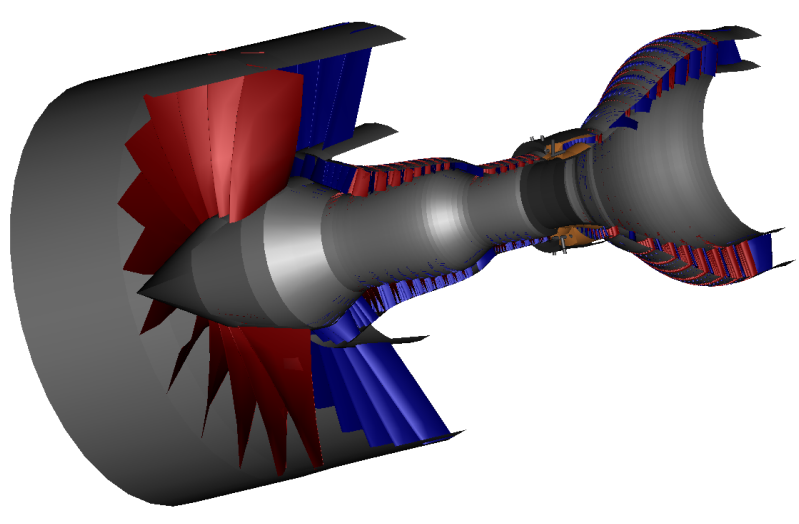

(b) 3D-view of the engine

Fig. 5 Geometry of the reference engine model.

more or less stages are required than are available for the reference engine, the blade parameters of the second last stage are copied or removed. The appearance of the last stage might be special, e.g. due to its function of straightening the outflow.

In order to generate the geometry of the whole turbofan, first the turbo components are geometrically modeled as described previously. Then the geometry of the combustion chamber and the ducts are created. Therefore, the radial positions of the inlet and outlet stations are prescribed by the turbo components. The normalized trajectory of the meanline is provided by a B-spline in the case of ducts. In order to create a continuous transition at the hub and tip to the subsequent components, the gradient at the start and end points of the B-splines is adapted accordingly. The duct length depends on the radius difference to be covered and is not allowed to be less than a minimum length. In a final step, the components are positioned axially and brought together to form a complete two-dimensional engine annulus. The geometry of the reference engine model generated by the applied knowledge-based method is shown in figure $5 \mathrm{a}$ The engine length measured from the fan rotor to the TEC outlet of the scaled GA is reproduced by the applied method with a relative deviation of $0.6 \%$.

The number of blades for each row is determined based on prescribed values for the PR of rotors and stators (see Tab. 47). The PR of the fan rotor is selected to result in 20 fan blades, which is the blade count in the case of the Trent 1000 engine [23]. Due to missing information on other blade numbers, empirical pitch ratios according to [11] are assumed. Component-specific standard profiles for the blades are selected from a database and an assumption for the blade stagger angle is made, which allows the entire engine to be displayed in 3D (Fig. 5b). This 3D geometry is the result of a knowledge-based method combined with thermodynamic data. No aerodynamic design methods are applied. Accordingly, the generated geometry is limited in further use to the estimation of the installation space, the rough visualization of the engine geometry and the application of correlation-based weight methods. A detailed description of the knowledge-based method for geometry estimation including a discussion about the applicability for conceptual design purposes will be presented in [29]. 


\section{E. Weight Estimation}

The weight estimation is based on the generated engine geometry and thermodynamic cycle data that includes the main sizing operating points MTO, TOC and CR. The component-based approach according to [30] and the part-based approach according to [31, 32] are applied. Maximum operating conditions are taken into account in both cases. The component-based procedure delivers the weight of the main engine components like compressors and turbines. The part-based process provides stage-wise information on the mass of parts like blades, disks, casing and connecting hardware. Weight estimates for the combustor, the structure and accessories are also available. Whereas the component-based procedure has mainly an empirical base, the part-based method includes more physical approaches. For example the disk weight is not only a function of geometry but also of blade pull stress and material yield strength. The material database within the GTlab framework is used to provide different materials for the engine components. The influence of the material temperature on the yield strength is taken into account for the operating condition with maximum load. The selected materials for the reference engine are given in Tab. 4 Titanium is assumed for the compressor ducts and a nickel-based alloy for the turbine ducts as well as for the combustor. Containment and blade-off considerations according to Fedorchenko as described in [20] lead to an estimate for the casing thickness. In the case of the part-based procedure, the blade mass is estimated considering the blade geometry and the blade volume factor $K_{\mathrm{v}}$, which is an empirical constant. For the turbo components except the fan the latest technology update for $K_{\mathrm{v}}$ is taken from [11]. Because there is a range of $K_{\mathrm{v}}$ given for the fan, the values initially published in [32] are used for this component. The selected blade volume factors in Tab. 4 are kept constant for all engines to maintain the technology level of blade design. The bare engine weight estimates for the reference engine model are compared to the weight of the Trent 1000-R3 taken from [21] in Tab. 5 and calibration factors $\mathrm{C}_{f}$ are introduced. Furthermore, the determined relative location of the center of gravity is presented.

Table 5 Weight and center of gravity estimates for the reference engine model.

\begin{tabular}{|l|cccc|c|}
\hline Method & $\begin{array}{c}W_{\text {Prediction }} \\
{[\mathrm{kg}]}\end{array}$ & $\begin{array}{c}W_{\text {Trent-1000-R3 }} \\
{[\mathrm{kg}]}\end{array}$ & $\begin{array}{c}\Delta W \\
{[\%]}\end{array}$ & $\begin{array}{c}\mathrm{C}_{f} \\
{[-]}\end{array}$ & $\begin{array}{c}\text { COG } \\
{[-]}\end{array}$ \\
\hline \hline Component-based [30] & 5679 & 6114 & -7.11 & 1.077 & 0.585 \\
Part-based [32] & 6272 & 6114 & +2.59 & 0.975 & 0.520 \\
\hline
\end{tabular}

With a relative deviation of $2.6 \%$ the part-based approach results in a bare engine weight close to the Trent 1000-R3. But also the component-based procedure delivers an appropriate value with a relative deviation of $-7.1 \%$. It is pointed out that this accuracy is not representative for the applied methods and in general a significantly increased uncertainty has to be expected, especially for weight estimates of individual components or parts. The relative location of the center of gravity is predicted to be 0.52 respectively 0.59 for the reference engine model. The deviation between the applied methods is mainly attributed to a heavy estimate for the LPT in case of the component-based approach, which leads to a shift of the center of gravity to the rear.

The calculated calibration factors are applied for the weight models to match the bare engine weight of the Trent 1000-R3 in case of the reference engine model. A detailed breakdown of the calibrated component weights estimated with both approaches is given in Tab. 6 The part-based weight method is selected for the following studies due to the more accurate weight estimation. The suitability of the weight methods for the application in the context of conceptual engine design will be further investigated in [29]. 
Table 6 Breakdown of calibrated weight estimates on component level for the reference engine model.

\begin{tabular}{|c|c|c|c|c|}
\hline \multirow[b]{2}{*}{ Component } & \multicolumn{2}{|c|}{ Part-Based Approach [31, 32] } & \multicolumn{2}{|c|}{ Component-Based Approach [30] } \\
\hline & $\begin{array}{c}\text { Weight } \\
{[\mathrm{kg}]}\end{array}$ & $\begin{array}{c}\text { Share } \\
{[\%]}\end{array}$ & $\begin{array}{c}\text { Weight } \\
{[\mathrm{kg}]}\end{array}$ & $\begin{array}{c}\text { Share } \\
{[\%]}\end{array}$ \\
\hline Turbo Components & 3758.9 & 61.48 & 4530.0 & 74.09 \\
\hline Fan & 1728.8 & 28.28 & 1693.1 & 27.69 \\
\hline IPC & 591.6 & 9.68 & 562.2 & 9.20 \\
\hline HPC & 147.6 & 2.41 & 97.2 & 1.59 \\
\hline HPT & 121.6 & 1.99 & 121.7 & 1.99 \\
\hline IPT & 346.2 & 5.66 & 224.4 & 3.67 \\
\hline LPT & 823.0 & 13.46 & 1831.4 & 29.95 \\
\hline Combustor & 120.8 & 1.98 & 133.2 & 2.18 \\
\hline Structure & 1622.9 & 26.54 & 839.4 & 13.73 \\
\hline ICD 1 & 33.4 & 0.55 & - & - \\
\hline ICD 2 & 45.0 & 0.74 & - & - \\
\hline ITD 1 & 34.8 & 0.57 & - & - \\
\hline ITD 2 & 20.9 & 0.34 & - & - \\
\hline TEC & 114.4 & 1.87 & - & - \\
\hline Fan Frame & 546.4 & 8.94 & - & - \\
\hline Intermediate Frame & 153.3 & 2.51 & - & - \\
\hline Turbine Frame & 47.3 & 0.77 & - & - \\
\hline TEC Frame & 243.2 & 3.98 & - & - \\
\hline HP Shaft & 0.6 & 0.01 & - & - \\
\hline IP Shaft & 27.6 & 0.45 & - & - \\
\hline LP Shaft & 355.9 & 5.82 & - & - \\
\hline Accessories & 611.4 & 10.00 & 611.4 & 10.00 \\
\hline Bare Engine Weight & 6114.0 & 100.00 & 6114.0 & 100.00 \\
\hline
\end{tabular}

\section{Design Space Exploration}

In this section, the engine design space will be explored. Therefore, the important thermodynamic cycle parameters $T_{4}$, OPR and BPR are varied and different thrust requirements are considered. An engine is designed for each parameter combination using the methodology described in section VI. All parameter variations are performed starting from the reference engine. It will be verified whether the design methodology leads to physically reasonable trends regarding the thermodynamic performance, geometry and weight. Furthermore, it is investigated how engine design variables that will not be covered by the rubber engine model can be selected optimally in terms of the overall aircraft system. To evaluate a specific design on the overall system level, the change in block fuel $\Delta \mathrm{FB}$ relative to the reference engine is calculated approximately using Eq. 1 .

$$
\Delta \mathrm{FB}=\mathrm{TF}_{\mathrm{TSFC}} \cdot \frac{\mathrm{TSFC}-\mathrm{TSFC}_{\mathrm{ref}}}{\mathrm{TSFC}_{\mathrm{ref}}} \cdot 100+\mathrm{TF}_{W} \cdot\left(W-W_{\mathrm{ref}}\right)+\mathrm{TF}_{D} \cdot\left(D-D_{\text {ref }}\right),[\%]
$$

A change in the fuel consumption, the weight or the diameter of the engine lead to changes in the required fuel mass to accomplish the mission, the nacelle wetted area, the total system weight and therefore the aircraft lift and drag. 
To basically account for these effects, the trading factors TF for the typical mission of the Boeing 737-8 model from Tab. 1 1are used, since this mission is flown most often. The engine design is based on the thrust requirements for the design range mission and this also applies to the TSFC values that will be used to evaluate Eq. 1. But it is assumed that relative changes in TSFC are also valid for the slightly lower thrust requirements of the typical mission. Furthermore, a trading factor for the engine diameter $\mathrm{TF}_{D}$ is applied, which can not be published due to confidentiality restrictions. The influence of the engine length on the block fuel is neglected due to a missing trading factor. The values for $\mathrm{TF}_{i}$ do not include possible snowball effects resulting from a redesign of aircraft components and are assumed to be constant over the entire design space. Resulting changes in the required thrust at different operating conditions, which potentially influence the engine design, are also neglected. For that reason, this procedure is limited to the estimation of qualitative trends at the block fuel level. In the following, three different parameter studies are presented and discussed. For each study the engine design methodology is applied and the investigated parameter space is then restricted by the limits given in Tab. 3, whereby the operating conditions CR, TOC and hot day MTO are taken into account.

\section{A. Parameter Study: BPR, T4 and OPR variation}

Engines are designed for different combinations of $T_{4}$, OPR and BPR, but for constant thrust requirements and flight conditions. Various chosen parameter trends are illustrated in Fig. 6 and 7. The abscissa shows $T_{4}$ and the ordinate OPR, both at the CR condition. For these plots the BPR of the reference engine is maintained with a value of 9.75 and lines of constant fan tip radius $R_{t}$, which varies between 1.3 and approximately $1.6 \mathrm{~m}$, are drawn. The design space is restricted by the critical temperature limits for $T_{3}$ and $T_{4}$, which are reached at hot day MTO. An increase in the OPR at CR leads to a similarly higher value at MTO and results in an increased outlet temperature of the HPC. Thereby, the $T_{3}$-limit is reached at a certain OPR. The same applies to $T_{4}$ at $\mathrm{CR}$ and the corresponding temperature limit that is also reached at hot day MTO. A wide range of the parameter space is excluded and shaded due to the restrictions. Only the lower left corner leads to valid engine designs in line with the temperature limitations.

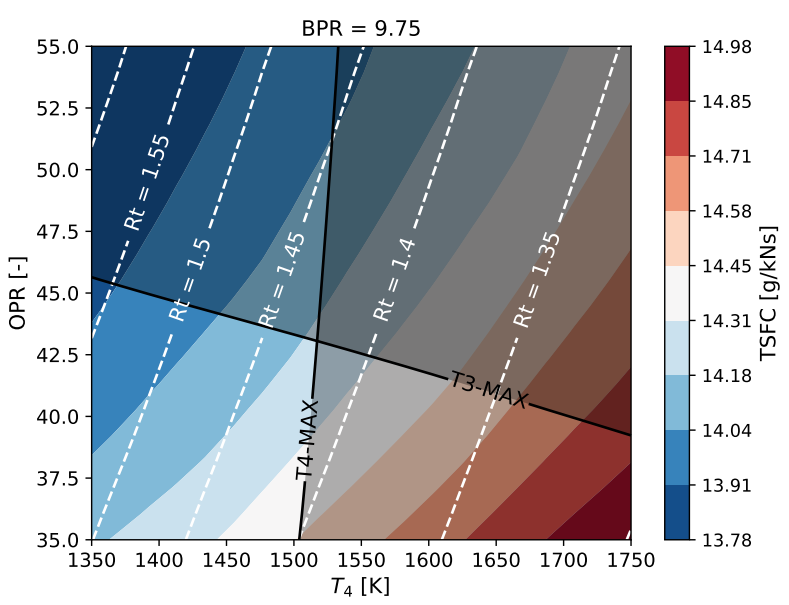

(a) Thrust specific fuel consumption at $\mathrm{CR}$

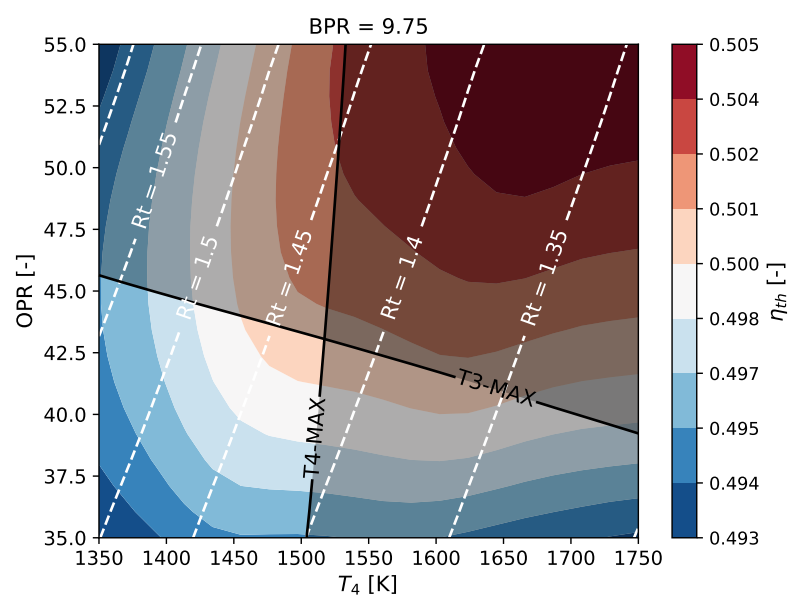

(b) Thermal efficiency at CR

Fig. 6 TSFC and thermal efficiency $\eta_{\text {th }}$ for engine designs with different $T_{4}$ and OPR at CR but a constant BPR. Lines of constant fan tip radii $R_{t}$ and the restrictions due to temperature limitations for $T_{3}$ and $T_{4}$ are shown.

The TSFC at CR is depicted in Fig. 6a and varies by $8.7 \%$ over the entire range and by $4.9 \%$ over the valid parameter space. The TSFC depends on the thermal efficiency $\eta_{\text {th }}$ and the propulsive efficiency $\eta_{\text {prop. }}$. The thermal efficiency increases with simultaneously raising OPR and $T_{4}$ (see Fig. $6 \mathrm{~b}$ ) and varies at CR between 49.3 and $50.5 \%$ over the entire parameter space. The reference engine, which is located at the intersection of the temperature limit lines, has been well positioned in terms of $\eta_{\text {th }}$. The course of the propulsive efficiency in Fig. 7a follows mainly the engine tip radius. It varies widely between 78.8 and $85.8 \%$. The highest $\eta_{\text {prop }}$ is reached at low $T_{4}$ and high OPR. Here an increase in OPR at a fixed $T_{4}$ leads to a higher $T_{3}$, a lower specific heat added by the combustor and a lower core nozzle velocity. The velocity of the bypass nozzle is adjusted to match the ideal nozzle velocity ratio and is also reduced, whereby the fan pressure ratio is decreased. To deliver the prescribed thrust, the mass flow through the hole engine and 
hence the fan diameter increase. The lower jet velocities lead to a higher propulsive efficiency. Due to the decrease in the fan pressure ratio, the fan efficiency increases and the higher mass flow results in a slightly better efficiency of the LPT. Thereby, the transmission efficiency of the low pressure system and hence the jet velocity at the bypass nozzle rise, slightly counteracting the previously described effect. For a constant OPR, an increase in $T_{4}$ leads to higher jet velocities, smaller mass flows as well as smaller engine radii and therefore a lower $\eta_{\text {prop }}$. In total, the propulsive efficiency outweighs the thermal efficiency resulting in the best TSFC at high OPR, low $T_{4}$ and large diameters. To achieve the lowest TSFC in the valid range for both a fixed engine diameter and a constant $T_{4}$, the OPR should be selected to reach the $T_{3}$-limit at MTO.

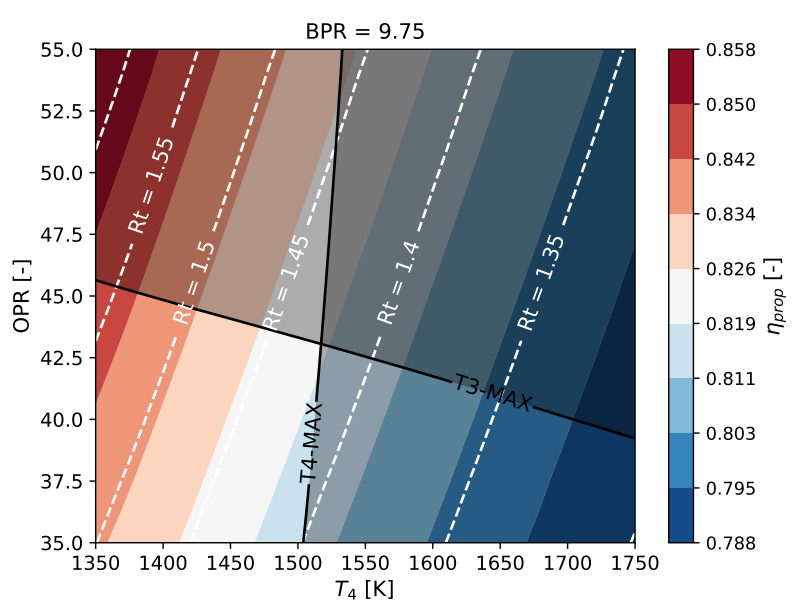

(a) Propulsive efficiency at CR

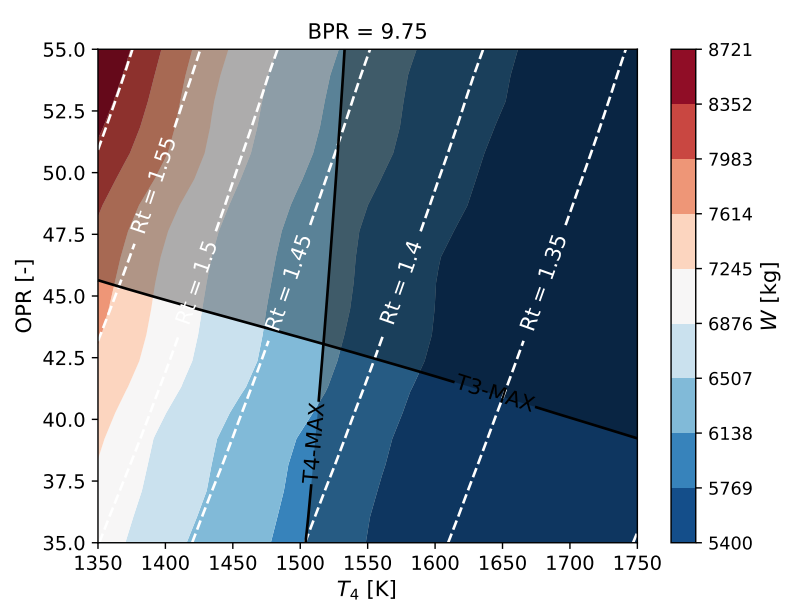

(b) Bare engine weight predicted with part-based approach

Fig. 7 Propulsive efficiency $\eta_{\text {prop }}$ and engine weight for engine designs with different $T_{4}$ and OPR at CR but a constant BPR. Lines of constant fan tip radii $R_{t}$ and the temperature limitations for $T_{3}$ and $T_{4}$ are shown.

The bare engine weight predicted by the part-based approach is shown in Fig. $7 \mathrm{~b}$ and follows mainly the engine size given by the fan tip radius. The weight varies over the entire parameter space between $5.4 \mathrm{t}$ at small and $8.7 \mathrm{t}$ at large engine diameters. The waves in the lines of constant weight are induced by changes in the stage number of components. The trends described are similar for all investigated bypass ratios between 8 and 14 .

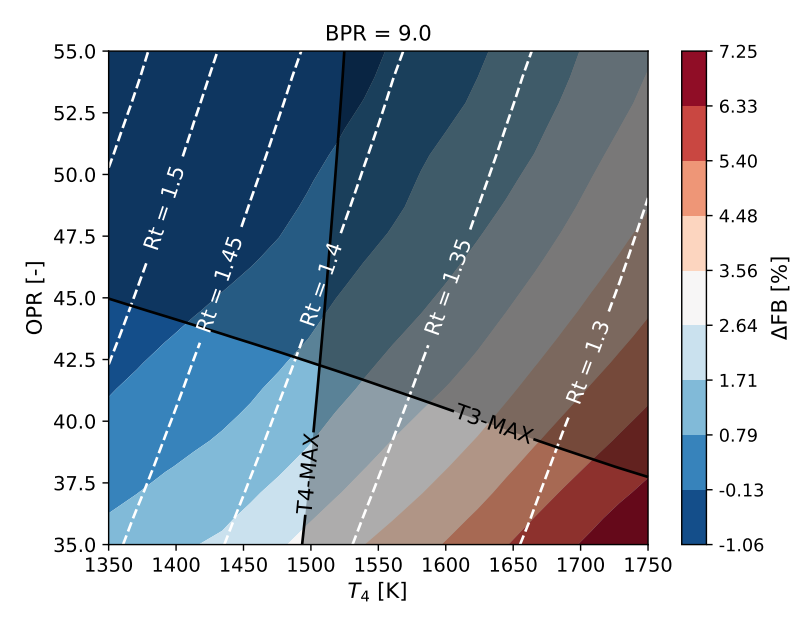

(a) Change in block fuel for BPR $=9$

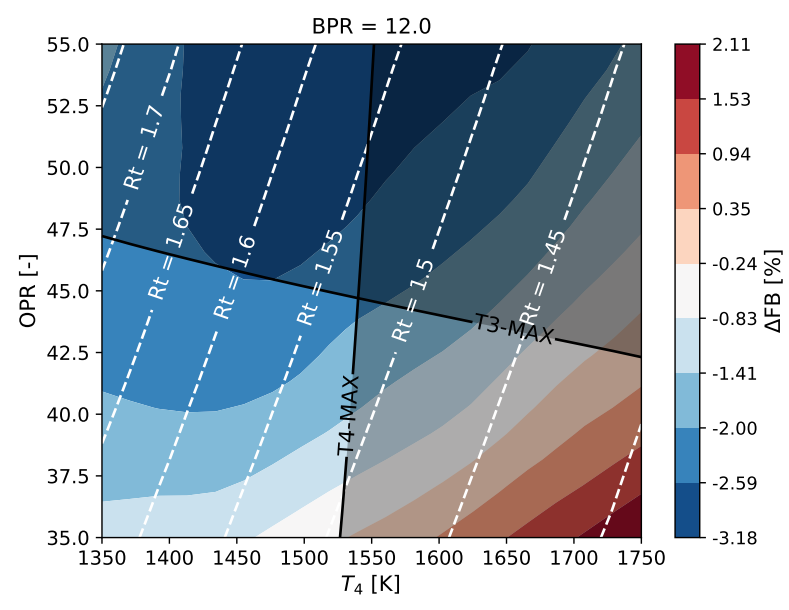

(b) Change in block fuel for BPR $=12$

Fig. 8 Change in block fuel relative to the reference engine for engine designs with different $T_{4}$ and OPR at CR. Lines of constant fan tip radii $R_{t}$ and the temperature limitations for $T_{3}$ and $T_{4}$ are shown. 
In Fig. 8 the different designs are evaluated on the block fuel level taking into account changes in the TSFC, weight and diameter compared to the reference engine. For BPR $=9$ the lowest fuel burn occurs at high BPR and low $T_{4}$ (see Fig. 8a). The low TSFC in this region outweighs the disadvantages coming from heavier engines and larger diameters. In the case of $\mathrm{BPR}=12$, it is slightly different as shown in Fig. $8 \mathrm{~b}$. The higher BPR results in larger fans and hence heavier engines. This leads to a shift of the optimum in $\triangle \mathrm{FB}$ to higher values of $T_{4}$ at $\mathrm{CR}$ compared to $\mathrm{BPR}=9$. The optimum in $\triangle \mathrm{FB}$ for a constant $T_{4}$ is located at the highest OPR in the range of the parameter study, except for values close to $T_{4}=1350$. Furthermore, the valid design space is extended due to the increase in BPR, which is attributed to the higher thrust lapse of the engines and the therefore lower temperatures at MTO. For all investigated values of the BPR, the OPR should be selected as high as possible within the temperature limitations to minimize the block fuel of the overall system. Although possible snowball effects are neglected and simplifying assumptions are made by utilizing trading factors, the OPR will be set this way in the following studies.

\section{B. Parameter Study: BPR and $T_{4}$ variation with a constant $T_{3, \max }$}

A variation of the BPR and $T_{4}$ is depicted in Fig. 9. whereby for each engine design the OPR is selected to reach the maximum permissible $T_{3}$ at hot day MTO. The abscissa shows $T_{4}$ and the ordinate BPR at the CR condition. All engines fulfill the same thrust requirements at the operating conditions CR, TOC and MTO, but not all designs are in line with the temperature restrictions for $T_{4}$ and therefore the invalid range is shaded. The bare engine weight predicted with the part-based approach in Fig. 9avaries between 5.5 and $10.2 \mathrm{t}$ over the entire parameter space. The heaviest engines have a high BPR and a low $T_{4}$ since an increase in BPR principally leads to higher fan mass flows and a decrease in $T_{4}$ results in higher mass flows of both the core and bypass section. Both effects contribute to larger fan diameters as shown in Fig. 9b. Furthermore, the number of LPT stages increases with the BPR (see Fig. 9a). Larger fan diameters lead to lower rotational speeds of the low pressure shaft and thereby the stage loading of the LPT exceeds its limit at a certain point making additional stages necessary. The number of LPT stages is also slightly dependent on $T_{4}$. With an increase in $T_{4}$ at a fixed BPR the number of stages might be reduced. The lightest engines have a high $T_{4}$ and a medium BPR. Decreasing the BPR starting from there leads to smaller diameters and less LPT stages but also to a larger and heavier core due to an increased core mass flow. The heavier core outweighs the other effects resulting in an increased bare engine weight at low BPR values. The block fuel is degressivly reduced with growing BPR at a constant $T_{4}$ because larger diameters and heavier engines counteract the beneficial raise in the propulsive efficiency induced by higher BPR values (see Fig. 9b). The maximum block fuel reduction compared to the reference engine design with $\triangle \mathrm{FB}=-3.3 \%$ is achieved at a high BPR, a low $T_{4}$ and a large fan diameter. For a constant fan radius, $T_{4}$ should be selected as high as possible to minimize $\Delta \mathrm{FB}$. Therefore, $T_{4}$ is adjusted to match the maximum permissible temperature at hot day MTO in the following investigations.

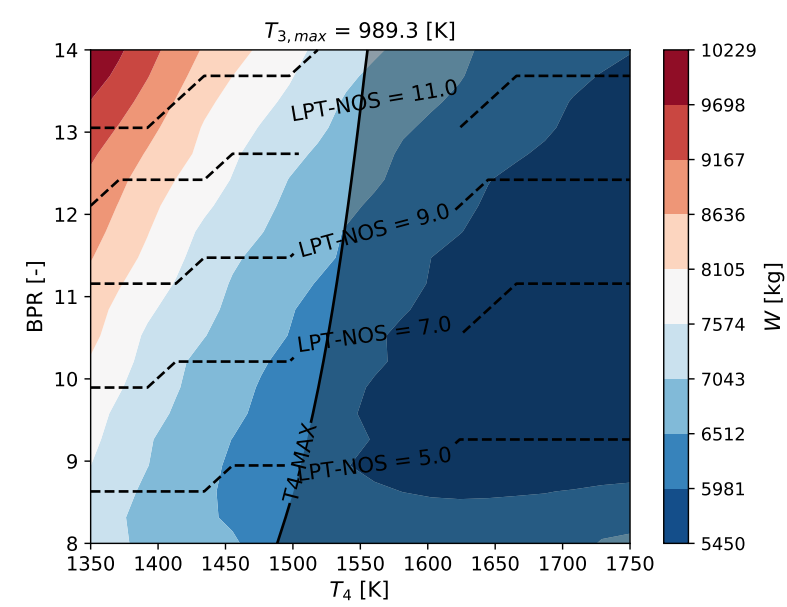

(a) Bare engine weight predicted with part-based approach

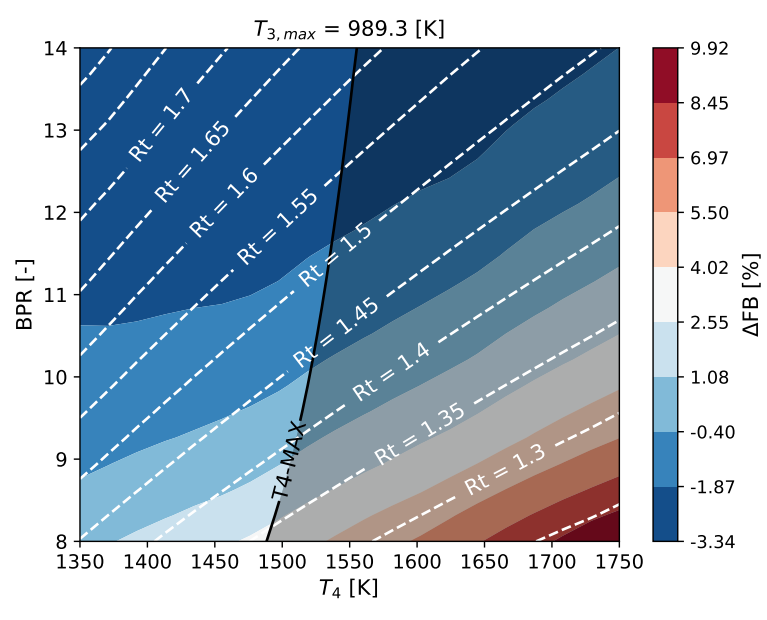

(b) Change in block fuel

Fig. 9 Bare engine weight and change in block fuel for engine designs with different $T_{4}$ and BPR at CR. The OPR at CR is adjusted to match the $T_{3}$-limit at hot day MTO. The engine fan tip radii $R_{t}$, the number of LPT stages and the maximum temperature limit for $T_{4}$ taking into account all operating conditions are shown. 


\section{Parameter Study: BPR and Thrust variation}

In the following parameter study, the engine BPR and the required thrusts at CR and MTO are varied. The investigated parameter space is build by an absolute value for the CR thrust $\mathrm{FN}_{\mathrm{CR}}$ and the ratio of MTO to CR thrust $\mathrm{FN}_{\text {Ratio}}$, which is in the case of the reference engine $\mathrm{FN}_{\mathrm{Ratio}}=8.21$. Thereby, unrealistic combinations, e.g. a small $\mathrm{FN}_{\mathrm{CR}}$ and a very high thrust demand at MTO are avoided, because the MTO thrust is automatically scaled with the CR requirement to a reasonable range. A variation of the MTO thrust is then possible by varying $\mathrm{FN}_{\text {Ratio. }}$. The thrust at TOC is approximately estimated by assuming a constant ratio between CR and TOC. The flight conditions are constant for all designs and the OPR as well as $T_{4}$ are selected to reach the maximum temperature limits. Figure 10 shows the TSFC at CR for different engine designs at two planes of the parameter space. The BPR is varied between 8 and 12 . Higher BPR values are not considered, since then more than ten LPT stages become necessary. The CR thrust spans a wide range between 30 and $60 \mathrm{kN}$ and $\mathrm{FN}_{\mathrm{Ratio}}$ is varied between 6.6 and 9.8.

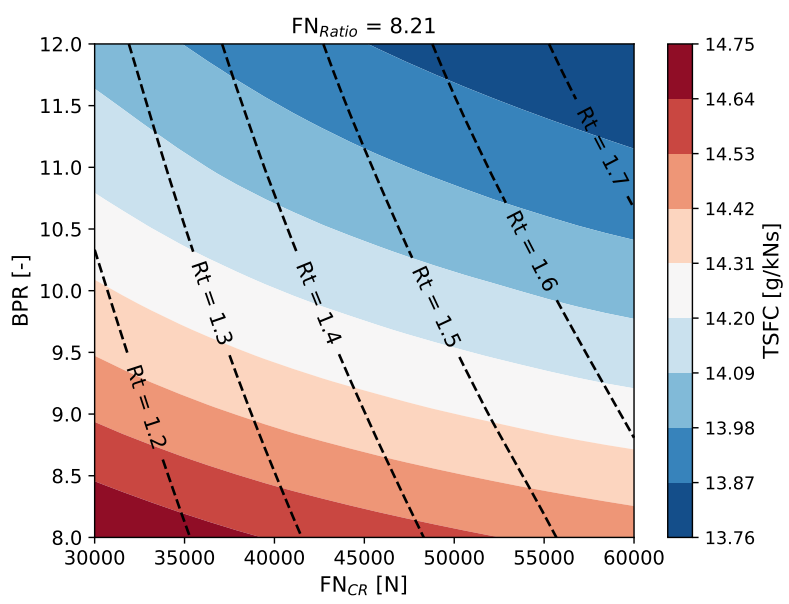

(a) TSFC at $\mathrm{CR}$ as a function of $\mathrm{FN}_{\mathrm{CR}}$ and $\mathrm{BPR}$

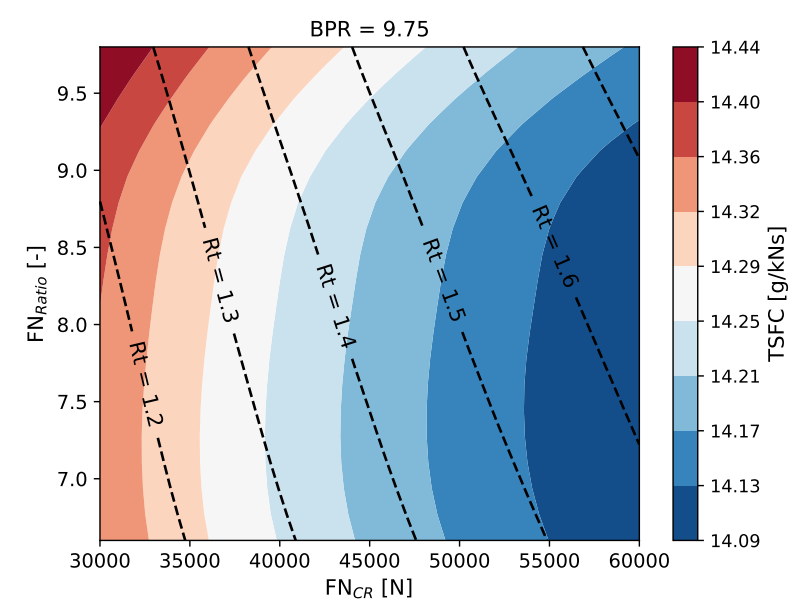

(b) TSFC at $\mathrm{CR}$ as a function of $\mathrm{FN}_{\mathrm{CR}}$ and $\mathrm{FN}_{\text {Ratio }}$

Fig. 10 TSFC for a variation of the BPR at CR, the thrust at CR and the ratio of hot day MTO to CR thrust. The OPR and $T_{4}$ at CR are adjusted to reach the temperature limits at hot day MTO. Lines with constant engine fan tip radii $R_{t}$ are drawn.

The TSFC at CR is presented as a function of $\mathrm{FN}_{\mathrm{CR}}$ and $\mathrm{BPR}$ in Fig. 10a for a constant $\mathrm{FN}_{\mathrm{Ratio}}$ according to the reference engine model. An increase in the BPR for a constant $\mathrm{FN}_{\mathrm{CR}}$ leads to higher fan mass flows, larger diameters and an increased propulsive efficiency. Increasing the thrust requirements at CR for a constant BPR results also in larger diameters and generally higher mass flows through the core and the bypass. Thereby, the component dimensions grow and their polytropic efficiency raises slightly due to the size effect. In total the TSFC reaches the lowest values at high CR thrust and high BPR.

The influence of the MTO thrust is discussed on the basis of Fig. 10b that shows the TSFC as a function of FN $\mathrm{CR}_{\mathrm{C}}$ and $\mathrm{FN}_{\text {Ratio }}$ for a constant BPR. When FN $\mathrm{FN}_{\text {Ratio }}$ is increased, $T_{4}$ at CR is reduced to do not exceed the $T_{4}$-limit at MTO. For the shown range, $T_{4}$ varies between $1620 \mathrm{~K}$ at $\mathrm{FN}_{\text {Ratio }}=6.6$ and $1420 \mathrm{~K}$ at $\mathrm{FN}_{\text {Ratio }}=9.8$ with almost no dependence on the CR thrust. The lower $T_{4}$ at $\mathrm{CR}$ for high values of $\mathrm{FN}_{\text {Ratio }}$ leads to lower nozzle velocities (see section VII.A) and therefore to higher mass flows, diameters and an increased propulsive efficiency. Similarly the $T_{3}$-limit for a higher MTO thrust is reached selecting lower OPR values at CR. In the range of $\mathrm{FN}_{\text {Ratio }}=6.6$ to 9.8 the OPR decreases from 51 to 37. Again there is no significant influence of the CR thrust on the OPR. The increased OPR results in a higher thermal efficiency at low values for FN $\mathrm{F}_{\text {Ratio }}$. The described changes in efficiency that are induced by the OPR and $T_{4}$ almost cancel each other. But the polytropic efficiency of the turbo components increases with higher CR thrusts due to a growing mass flow and component size. This affects the thermal efficiency and results in the TSFC trend presented in Fig. $10 \mathrm{~b}$ 


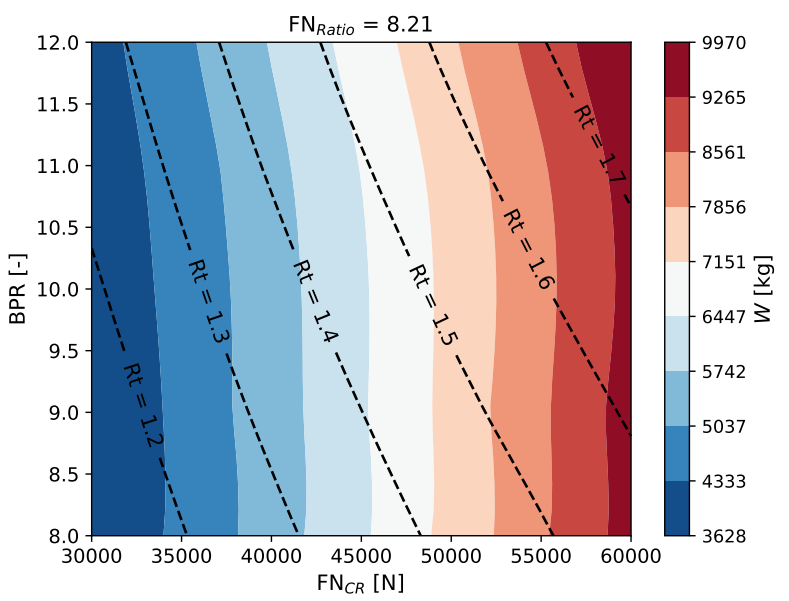

(a) Bare engine weight as a function of $\mathrm{FN}_{\mathrm{CR}}$ and $\mathrm{BPR}$

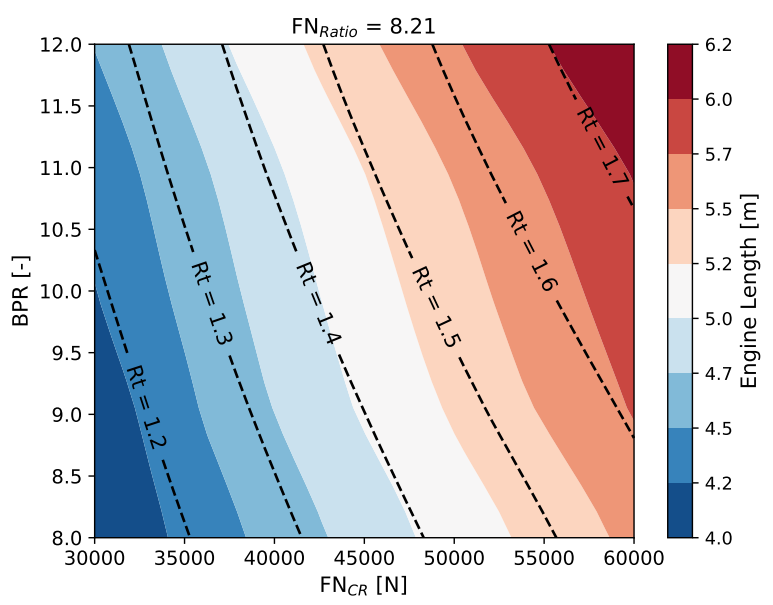

(c) Engine length as a function of $\mathrm{FN}_{\mathrm{CR}}$ and $\mathrm{BPR}$

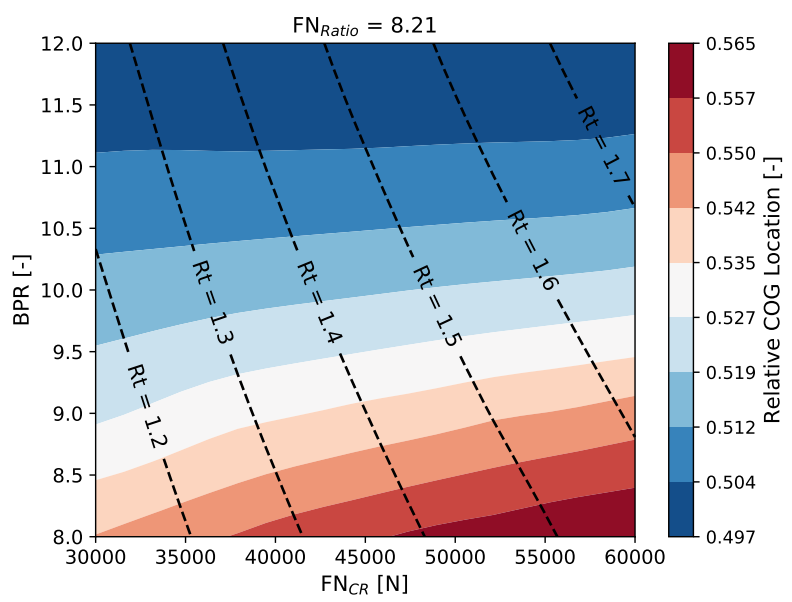

(e) $\mathrm{COG}$ as a function of $\mathrm{FN}_{\mathrm{CR}}$ and $\mathrm{BPR}$

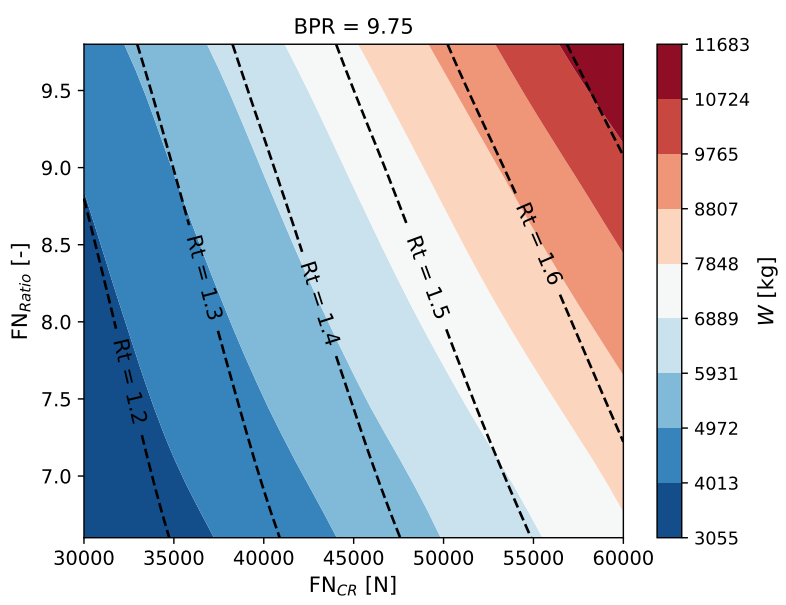

(b) Bare engine weight as a function of $\mathrm{FN}_{\mathrm{CR}}$ and $\mathrm{FN}_{\text {Ratio }}$

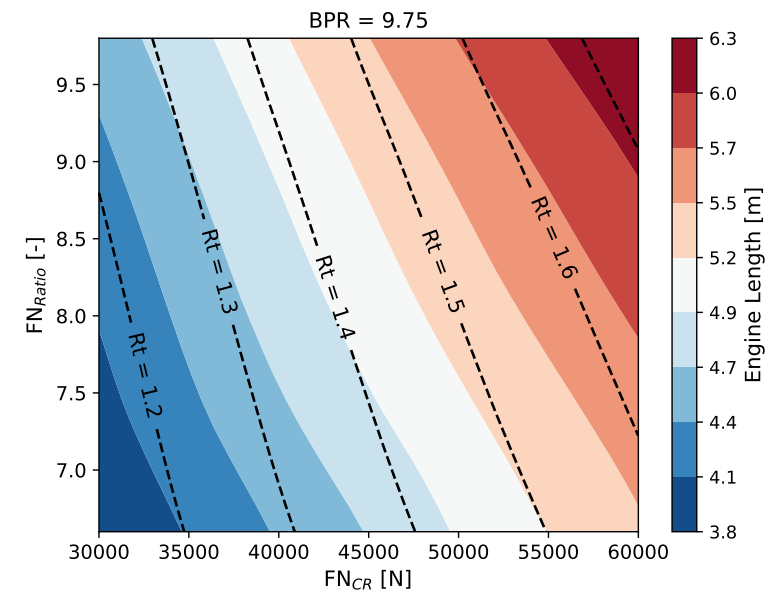

(d) Engine length as a function of $\mathrm{FN}_{\mathrm{CR}}$ and $\mathrm{FN}_{\text {Ratio }}$

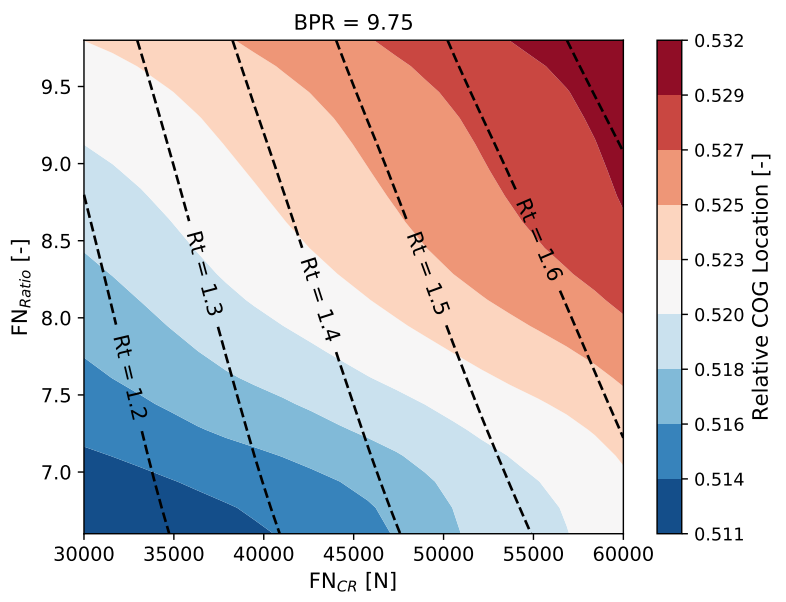

(f) $\mathrm{COG}$ as a function of $\mathrm{FN}_{\mathrm{CR}}$ and $\mathrm{FN}_{\mathrm{Ratio}}$

Fig. 11 Bare engine weight $W$ predicted with the part-based approach, engine length and relative location of the center of gravitiy for a variation of the BPR at CR, the thrust at CR and the ratio of hot day MTO to CR thrust. The OPR and $T_{4}$ at $\mathrm{CR}$ are adjusted to reach the temperature limits at hot day MTO. Lines with constant engine fan tip radii $R_{t}$ are drawn. 
Figure 11 shows the bare engine weight predicted with the part-based approach, the engine length and the relative location of the center of gravity in dependence on the parameters BPR, $\mathrm{FN}_{\mathrm{CR}}$ and $\mathrm{FN}_{\mathrm{Ratio}}$.

For a constant $\mathrm{FN}_{\text {Ratio }}$ and BPR, the bare engine weight $W$ increases strongly with the required thrust at CR due to higher engine mass flows and hence larger components, which is depicted in Fig. 11a. In the case of a growing BPR and constant thrust requirements, the fan weight, which follows mainly the fan tip radius, increases but the core engine shrinks and gets lighter. In total, the heavier fan and the additional LPT stages that may become necessary result in a slight gain of engine weight with increasing BPR at a constant thrust level. For a variation of the $\mathrm{FN}_{\text {Ratio }}$ at a constant $\mathrm{BPR}$, the previously described size effects are the important drivers for the bare engine weight, which follows mainly the fan radius (see Fig. 11b).

The engine length increases with growing thrust and diameter, which is apparent from Fig. 11c and 11d On the one hand, an increased BPR leads to smaller and shorter core components but on the other the fan gets longer and additional LPT stages are required. Overall, the engine length increases with the BPR (see Fig. 11c).

If the BPR is increased, the relative location of the center of gravity COG is shifted to the front due to a heavier fan and a shrunken core, although more LPT stages may be required (see Fig. 11e). By this effect, the COG varies over the parameter space between 0.5 and 0.57 . Compared to that, the COG shift induced by varying thrust requirements is rather small. All components get heavier with a growing CR thrust and therefore higher mass flows, which results in a slightly shift of the COG to the rear (see Fig. 11e and 11f). With an increasing FN $_{\text {Ratio, }}$, additional LPT stages may become necessary, e.g. at approximately $\mathrm{FN}_{\text {Ratio }}=7.25$ for the full range of $\mathrm{FN}_{\mathrm{CR}}$, which shifts the $\mathrm{COG}$ to the rear and results in the curved lines in Fig. 11f.
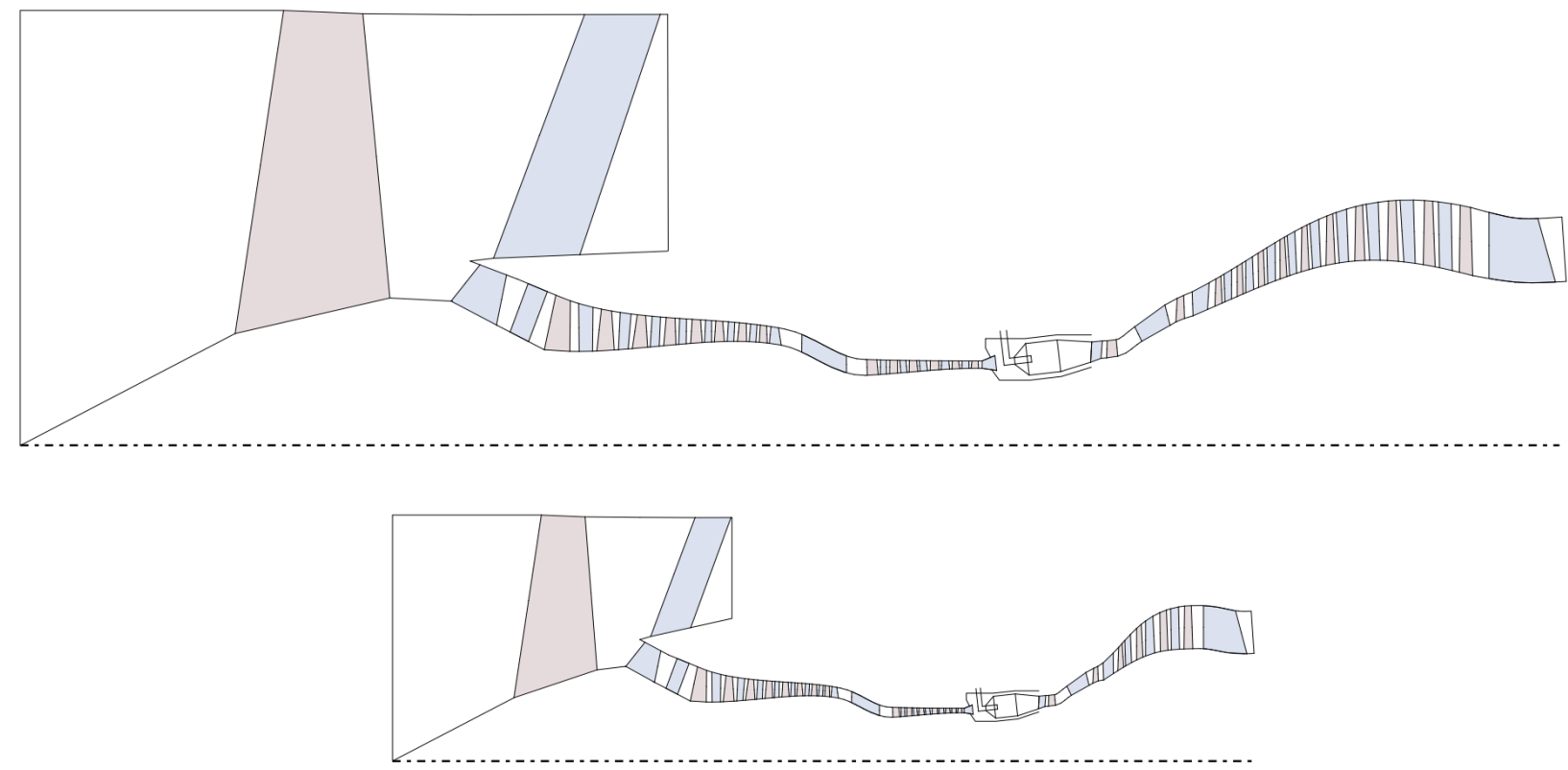

Fig. 12 2D-view of exemplary selected engines with high thrust and BPR respectively low thrust and BPR.

The 2D- and 3D-view of two designed engines are presented in Fig. 12 and 13 to give an impression of the geometries that are created with the applied knowledge-based procedure. The small engine with BPR $=8$ delivers a thrust of $30 \mathrm{kN}$ at CR and has with $\mathrm{FN}_{\text {Ratio }}=6.6 \mathrm{a}$ low MTO thrust. The larger engine has a high BPR of 12 and delivers $60 \mathrm{kN}$ at $\mathrm{CR}$ with $\mathrm{FN}_{\mathrm{Ratio}}=9.8$. In both cases the components show reasonable flow paths and are smoothly connected. Furthermore, the radial position of the LPT seems to leave enough space for the bypass duct and nozzle.

It can be concluded that in the context of the presented parameter studies the applied engine design methodology leads to physically reasonable trends regarding thermodynamic cycle parameters as well as the engine weight, length and center of gravity. Furthermore, engine geometries are created that seems sufficient for conceptual design purposes. 


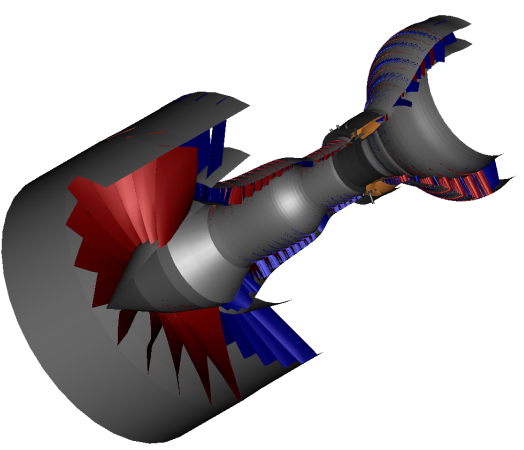

(a) Engine with low thrust and low BPR

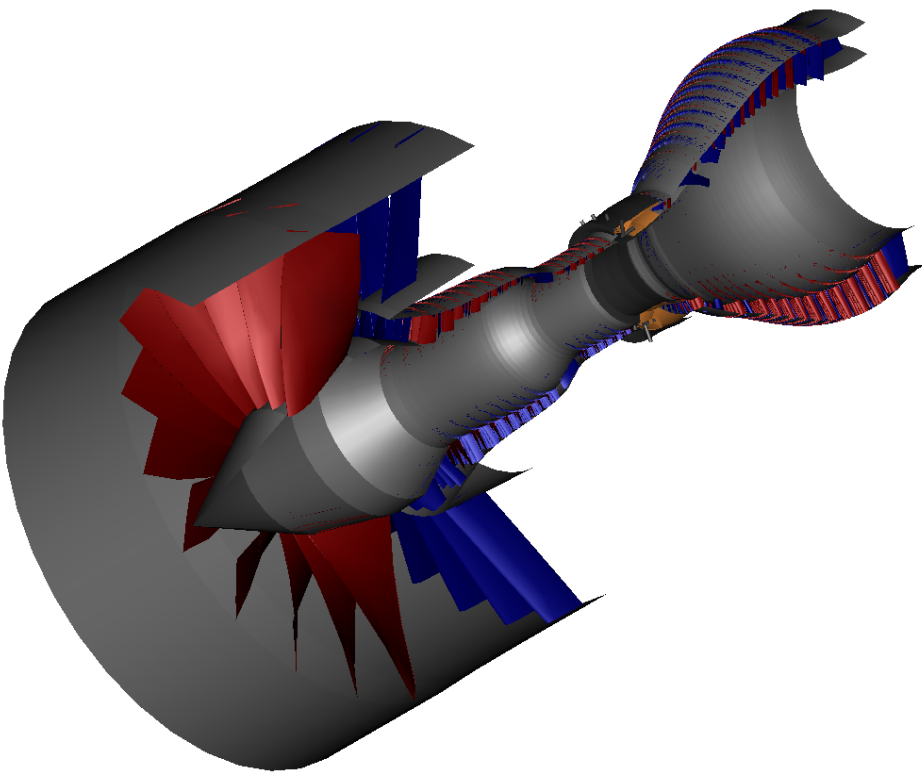

(b) Engine with high thrust and high BPR

Fig. 13 3D-view of exemplary selected engines with high thrust and BPR respectively low thrust and BPR.

\section{Rubber Engine Model Creation}

A three-dimensional parameter space is selected for the initial rubber engine model to keep complexity low and hence enable the comparison of various different models. Therefore, the thrust requirements at CR and MTO as well as the engine BPR are selected as particularly important variables in terms of engine sizing. While the operating point $\mathrm{CR}$ is decisive for the fuel consumption, MTO takes into account the maximum load point with the highest process temperature and maximum thrust. The thrust ratio $\mathrm{FN}_{\text {Ratio }}$ is used as model parameter instead of the absolute MTO thrust to ensure appropriate thrust combinations. Furthermore, not all combinations of thrust requirements and engine diameters lead to relevant designs [12], e.g. a combination of small thrust with large engine diameter will result in a very high BPR and an infeasible small core. For this reason, the BPR is used as input parameter for the rubber engine model, since it permits control over the fan diameter. The selected model parameter range for the rubber engine model is shown in Tab. 7 and covers the same design space as the previously described parameter study in section VII.C

Table 7 Parameter range of the rubber engine model.

\begin{tabular}{|lccc|}
\hline Model Parameter & Unit & Lower Bound & Upper Bound \\
\hline \hline BPR & {$[-]$} & 8 & 12 \\
$\mathrm{FN}_{\mathrm{CR}}$ & {$[\mathrm{kN}]$} & 30 & 60 \\
$\mathrm{FN}_{\text {Ratio }}$ & {$[-]$} & 6.6 & 9.8 \\
\hline
\end{tabular}

The rubber engine model delivers an engine design for each combination of the model parameters as described in section IV] For the creation of the surrogate models that are part of the hybrid surrogate-based concept, the automated process chain for engine design including the disciplines thermodynamics, geometry and weight is combined with meta-modelling capabilities provided from SMARTy. A separate surrogate model is build for each relevant output parameter of the rubber engine model. Different methods for design of experiment (DoE) including full-factorial sampling, latin-hypercube sampling, Sobol sequences and Halton sequences as well as a varying number of training points are used to create the surrogate models. Furthermore, different interpolation methods including linear and cubic interpolation, thin plate spline interpolation (TPS) and Kriging regression models are applied. Different combinations of 
methods are assessed with respect to the accuracy with which the results of the design process chain are reproduced by the rubber engine model. In total 200 calculated engine designs that are distributed in the parameter space by combining a full-factorial border with latin-hypercube sampling serve as validation data set. The validation samples are shown in Fig. 14. The performance parameters as well as the dimensions, the weight and the center of gravity of the validation engines will be predicted by means of different rubber engine models. The accuracy is assessed taking into account the maximum and mean relative deviations.

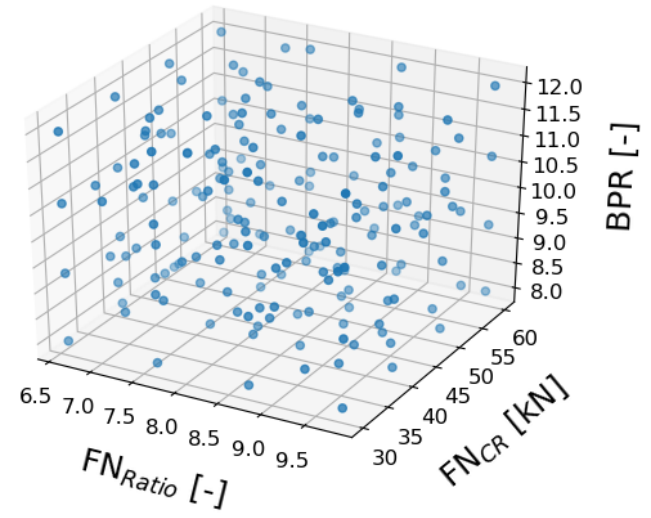

Fig. 14 Validation sampling that combines a full-factorial border with latin-hypercube sample points.

First of all, full-factorial sampling with a varying number of points between 8 and 1000 is combined with cubic interpolation without regression and a linear global trend to create rubber engine models. An overview of the achieved accuracy is presented in Tab. 8. Not only important thermodynamic cycle parameters at $\mathrm{CR}$, which are calculated by means of the performance tool, but also the engine radius, length, weight and center of gravity are considered.

Table 8 Accuracy of full-factorial sampling and cubic interpolation for different numbers of samples.

\begin{tabular}{|l|ccccc|ccccc|}
\hline \multirow{2}{*}{ Number of Samples } & \multicolumn{5}{|c|}{ Max. Error [\%] } & \multicolumn{5}{c|}{ Mean. Error [\%] } \\
\hline \hline TSFC & 8 & 27 & 64 & 125 & 1000 & 8 & 27 & 64 & 125 & 1000 \\
$W_{f}$ & 0.44 & 0.05 & 0.02 & 0.01 & 0 & 0.24 & 0.01 & 0.00 & 0.00 & 0 \\
$W_{\text {Intake }}$ & 0.44 & 0.05 & 0.02 & 0.01 & 0 & 0.24 & 0.01 & 0.00 & 0.00 & 0 \\
OPR & 2.04 & 0.47 & 0.19 & 0.14 & 0.06 & 0.81 & 0.12 & 0.02 & 0.02 & 0 \\
$T_{4}$ & 1.77 & 0.57 & 0.15 & 0.11 & 0.05 & 0.71 & 0.13 & 0.02 & 0.02 & 0 \\
$T_{3}$ & 0.79 & 0.23 & 0.11 & 0.08 & 0.03 & 0.32 & 0.05 & 0.01 & 0.01 & 0 \\
$A_{\mathrm{BN}}$ & 0.48 & 0.17 & 0.05 & 0.03 & 0.01 & 0.21 & 0.04 & 0.01 & 0.01 & 0 \\
$A_{\mathrm{CN}}$ & 2.66 & 0.76 & 0.24 & 0.19 & 0.08 & 0.81 & 0.16 & 0.03 & 0.02 & 0 \\
\hline$R_{t}$ & 7.93 & 1.06 & 0.37 & 0.22 & 0.07 & 4.58 & 0.25 & 0.07 & 0.03 & 0 \\
$L$ & 1.62 & 0.21 & 0.15 & 0.09 & 0.03 & 0.71 & 0.09 & 0.02 & 0.01 & 0 \\
$W_{\mathrm{cb}}$ & 3.22 & 1.68 & 1.74 & 1.62 & 1.71 & 0.87 & 0.48 & 0.39 & 0.53 & 0.3 \\
$\mathrm{COG}_{\mathrm{cb}}$ & 12.62 & 7.52 & 6.29 & 7.29 & 7.07 & 4.28 & 1.82 & 1.43 & 2.06 & 1.15 \\
$W_{\mathrm{pb}}$ & 2.95 & 2.62 & 2.08 & 2.54 & 2.43 & 0.54 & 0.55 & 0.44 & 0.62 & 0.34 \\
$\mathrm{COG}_{\mathrm{pb}}$ & 14.75 & 4.32 & 3.20 & 3.97 & 3.83 & 7.46 & 0.92 & 0.60 & 0.90 & 0.49 \\
\hline
\end{tabular}


The parameters $W$ and COG are shown for both the component-based (cb) and the part-based (pb) approach. The achieved accuracy for the thermodynamic parameters increases monotonously with the number of sample points. In the case of 8 points, only the corners of the parameter space are considered for model creation and even then the maximum relative deviations are smaller than $10 \%$ and the mean errors smaller than $5 \%$. For 64 training points or more, the thermodynamic parameters are matched with a maximum deviation less than $0.4 \%$ and a mean deviation less than $0.1 \%$. The same applies to $R_{t}$ but for the parameters $L, W$ and COG higher deviations are determined. At a certain point these deviations can not be reduced even if the number of samples is drastically increased to 1000 . The best predictions of $\mathrm{W}$ and COG are achieved with 64 sample points. This could be attributed to the fact that the corresponding rubber engine model was created with a sampling that include all full-factorial border points of the validation sampling. It can be summarized, that the errors regarding the thermodynamic parameters almost vanish if the number of sample points is increased. But at a certain point a further increase does not significantly improve the prediction of L, W and COG. In the case of 64 or more sample points, the weight according to the part-based approach is predicted with a maximum error less than $4 \%$ and a mean error less than $1 \%$. In the case of $\mathrm{L}$ and $\mathrm{COG}_{\mathrm{pb}}$ the maximum errors are less than $2 \%$ and the mean errors less than $0.6 \%$. It should be noted that all models here were created without regression and hence overfitting becomes more likely with increasing number of samples.

Table 9 Accuracy of different interpolation methods for a full-factorial sampling with 64 points.

\begin{tabular}{|c|c|c|c|c|c|c|c|c|c|c|}
\hline \multirow[b]{3}{*}{ Parameter } & \multicolumn{5}{|c|}{ Max. Error [\%] } & \multicolumn{5}{|c|}{ Mean. Error [\%] } \\
\hline & \multicolumn{3}{|c|}{ Interpolation } & \multicolumn{2}{|c|}{ Kriging } & \multicolumn{3}{|c|}{ Interpolation } & \multicolumn{2}{|c|}{ Kriging } \\
\hline & linear & cubic & tps & cubic & gaussian & linear & cubic & tps & cubic & gaussian \\
\hline TSFC & 0.06 & 0.02 & 0.04 & 0.03 & 0.03 & 0.01 & 0.00 & 0.01 & 0.00 & 0.00 \\
\hline$W_{f}$ & 0.06 & 0.02 & 0.04 & 0.03 & 0.03 & 0.01 & 0.00 & 0.01 & 0.00 & 0.00 \\
\hline$W_{\text {Intake }}$ & 0.66 & 0.19 & 0.45 & 0.19 & 0.19 & 0.09 & 0.02 & 0.05 & 0.03 & 0.02 \\
\hline OPR & 0.54 & 0.15 & 0.37 & 0.16 & 0.18 & 0.09 & 0.02 & 0.05 & 0.03 & 0.03 \\
\hline$T_{4}$ & 0.22 & 0.11 & 0.16 & 0.10 & 0.10 & 0.04 & 0.01 & 0.02 & 0.01 & 0.01 \\
\hline$T_{3}$ & 0.14 & 0.05 & 0.10 & 0.05 & 0.06 & 0.03 & 0.01 & 0.01 & 0.01 & 0.01 \\
\hline$A_{\mathrm{BN}}$ & 0.78 & 0.24 & 0.54 & 0.23 & 0.23 & 0.12 & 0.03 & 0.07 & 0.04 & 0.03 \\
\hline$A_{\mathrm{CN}}$ & 1.71 & 0.37 & 1.12 & 0.40 & 0.38 & 0.19 & 0.07 & 0.14 & 0.04 & 0.06 \\
\hline$R_{t}$ & 0.29 & 0.15 & 0.24 & 0.14 & 0.15 & 0.06 & 0.02 & 0.05 & 0.02 & 0.02 \\
\hline$L$ & 1.37 & 1.74 & 1.60 & 1.30 & 1.33 & 0.37 & 0.39 & 0.39 & 0.34 & 0.32 \\
\hline$W_{\mathrm{cb}}$ & 6.39 & 6.29 & 6.46 & 5.65 & 5.32 & 1.33 & 1.43 & 1.40 & 1.15 & 1.20 \\
\hline $\mathrm{COG}_{\mathrm{cb}}$ & 1.91 & 2.08 & 2.03 & 1.67 & 1.54 & 0.40 & 0.44 & 0.43 & 0.34 & 0.34 \\
\hline$W_{\mathrm{pb}}$ & 3.88 & 3.20 & 3.07 & 3.03 & 3.15 & 0.62 & 0.60 & 0.59 & 0.66 & 0.66 \\
\hline $\mathrm{COG}_{\mathrm{pb}}$ & 0.83 & 1.03 & 0.97 & 0.95 & 0.87 & 0.15 & 0.15 & 0.15 & 0.16 & 0.14 \\
\hline
\end{tabular}

Different interpolation and regression methods for a full-factorial sample with 64 points are compared in Tab. 9 . Linear, cubic and TPS interpolation are combined with a linear global trend and without regression. Furthermore, different Kriging approaches implemented in SMARTy have been assessed. The best accuracy is reached with a cubic spline kernel and a gaussian kernel with exponent optimization, both with regression and a quadratic global trend (see Tab. 96. A similar finding is presented in [13], where a Kriging regression model with a cubic spline kernel and quadratic regression has been identified as promising for a comparable problem. The deviations regarding the thermodynamic performance at CR and $R t$ are of comparable magnitude for cubic interpolation and both Kriging approaches. The rubber engine models that rely on linear and TPS interpolation feature significantly higher errors. In terms of engine length, weight and center of gravity, the Kriging regression models result partially in a slightly increased accuracy, especially in the case of the component-based weight estimate. It can be concluded that either cubic interpolation or Kriging should be selected to build the hybrid surrogate-based rubber engine model. 
It can be necessary to reduce the number of training points for the rubber engine model, e.g. if the engine design process is very time consuming or if a high dimensional design space is examined. Then DoE methods like latin-hypercube sampling, Halton sequences or Sobol sequences have advantages compared to a full-factorial sampling, e.g. with these DoE methods the parameter space can be covered more effectively with a small number of sample points. The accuracy of rubber engine models created with different DoE methods and numbers of samples is presented in Fig. 15. The maximum and mean error for the intake mass flow and the engine weight calculated with the part-based procedure are shown as a function of the number of training points. The 8 corner points of the parameter space are included in all created sample sets. The remaining points are generated by means of latin-hypercube sampling, Halton sequences and Sobol sequences. With these DoE methods, the mean error increases only slightly compared to a full-factorial sample of 27 points if the number of training points is reduced to 16 . The maximum deviations for 27 training points are higher compared to a full-factorial sampling but remain nearly constant or increase only slightly when less training points are used. This might lead to a sufficient accuracy for some applications. Between the samples generated with latin-hypercube sampling, Halton sequences and Sobol sequences no significant or systematic differences in accuracy can be observed.

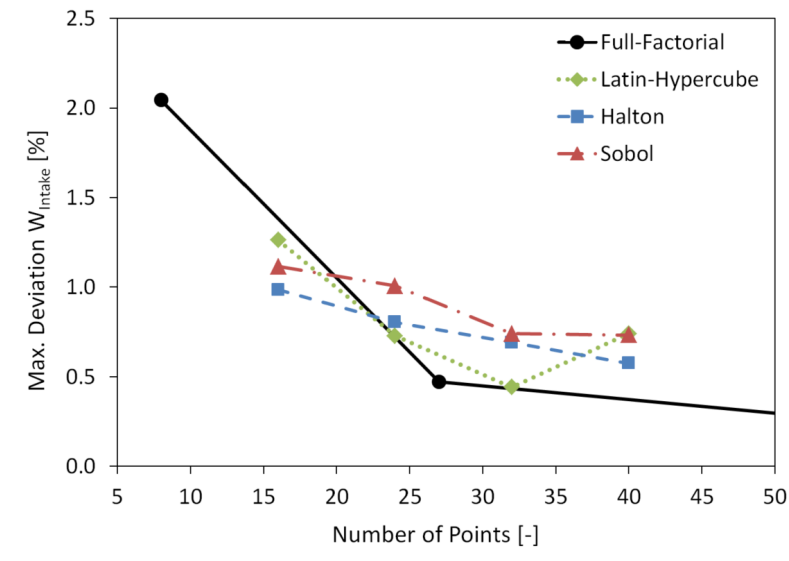

(a) Maximum deviation in engine mass flow

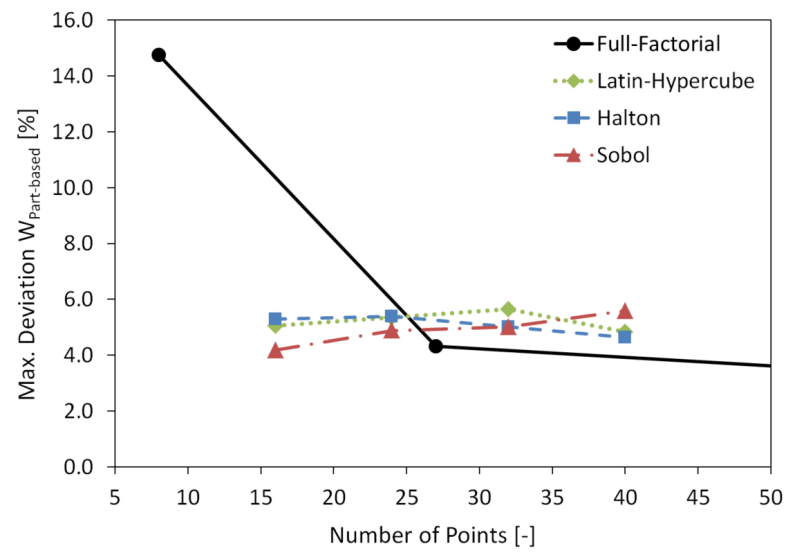

(c) Maximum deviation in bare engine weight

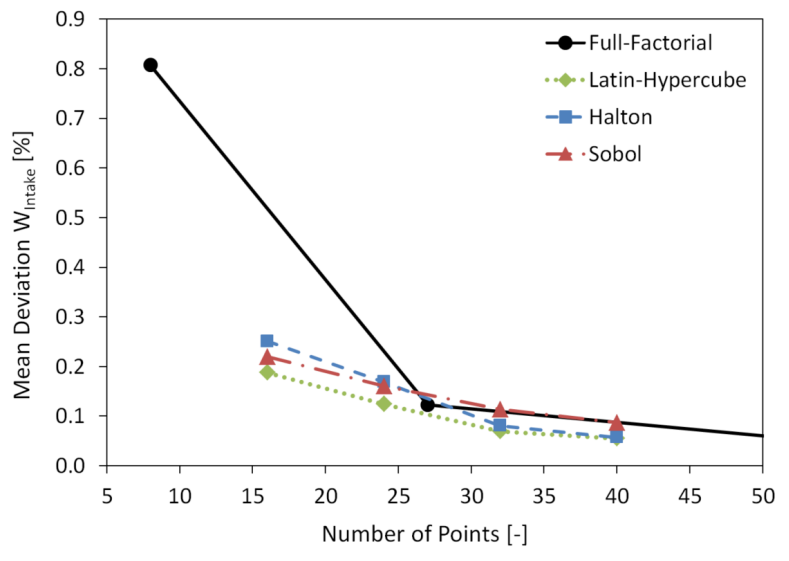

(b) Mean deviation in engine mass flow

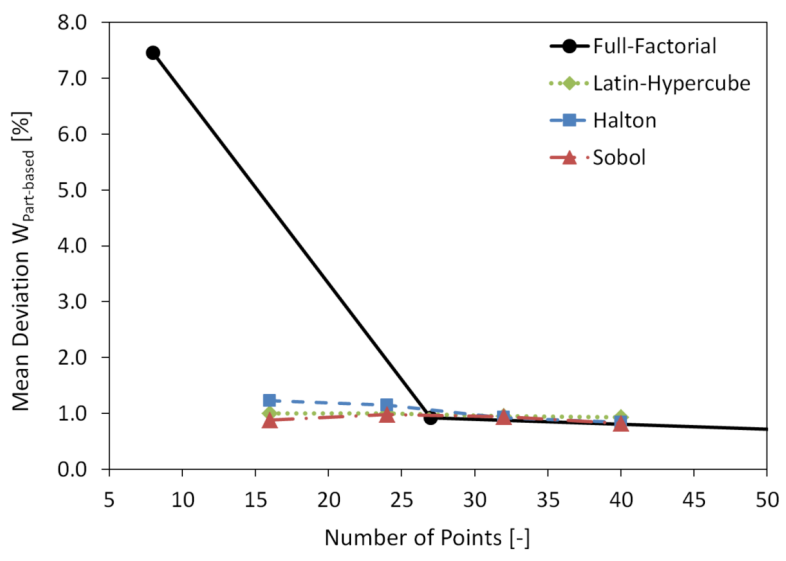

(d) Mean deviation in bare engine weight

Fig. 15 Maximum and mean deviation in the engine mass flow and weight for different DoE methods and cubic interpolation. For Latin-Hypercube, Halton and Sobol the corner points of the design space are included.

Neither a variation of the interpolation or regression method nor a varying number of sample points lead to weight predictions with a maximum relative error less than $3 \%$. In order to present the reason for that, the rubber engine model that relies on a full-factorial sample with 125 points and cubic interpolation is considered. Figure 16 exemplary shows the maximum relative deviation in bare engine weight in dependence on the BPR and $\mathrm{FN}_{\mathrm{CR}}$ for a constant $\mathrm{FN}_{\text {Ratio }}$. 
The highest errors occur at low BPR and medium to high CR thrust. In other regions the error is significantly lower. The number of LPT stages is shown for each training point of the rubber engine model. The stage number increases from 4 to 10 over the entire BPR range. Two additional stages become necessary in the ranges from BPR $=8$ to 9 and $\mathrm{BPR}=11$ to 12 . Additional validation engines are calculated for the parameter space shown in Fig. 16 by applying a full-factorial sampling with 400 points. The LPT weight of these validation engines, which is calculated by the part-based approach, is compared to the rubber engine model prediction in Fig 17

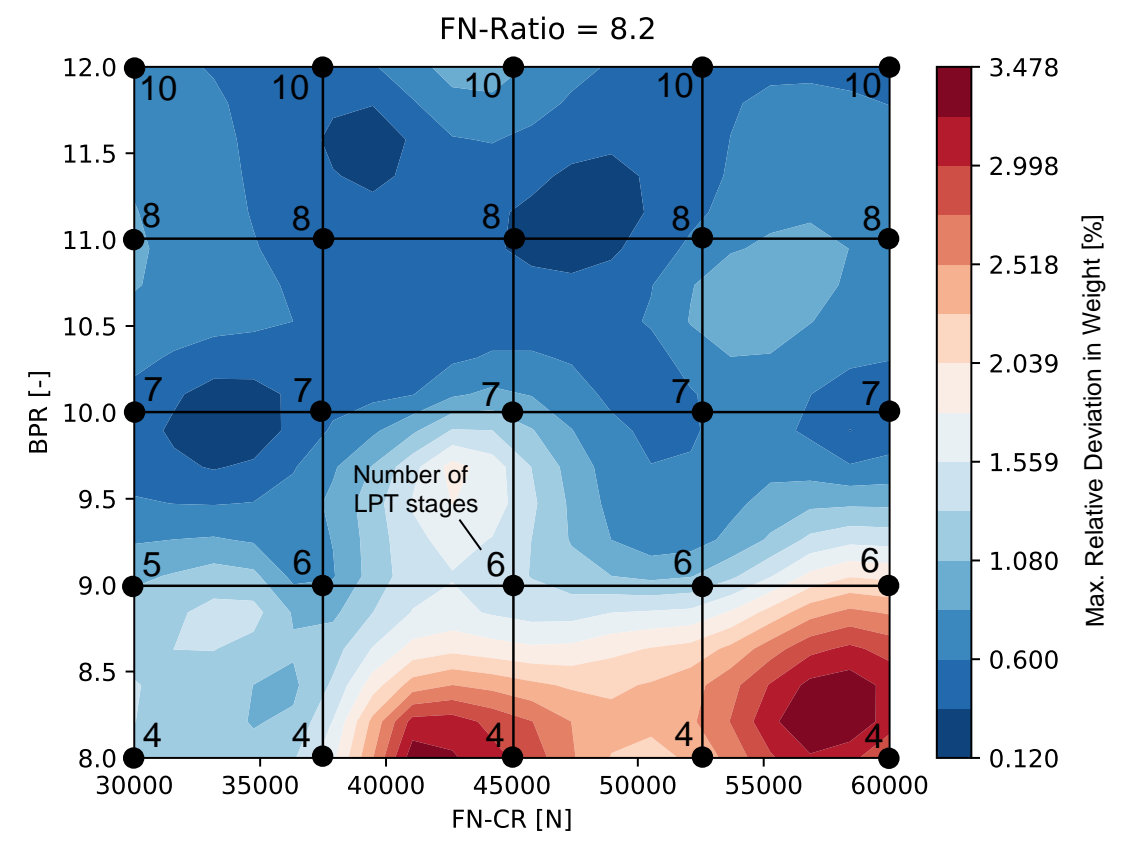

Fig. 16 Maximum relative error in bare engine weight (part-based approach) for a constant $\mathrm{FN}_{\text {Ratio }}$. The corresponding rubber engine model is based on full-factorial sampling with 125 points and cubic interpolation. For each sample point the number of LPT stages is shown.

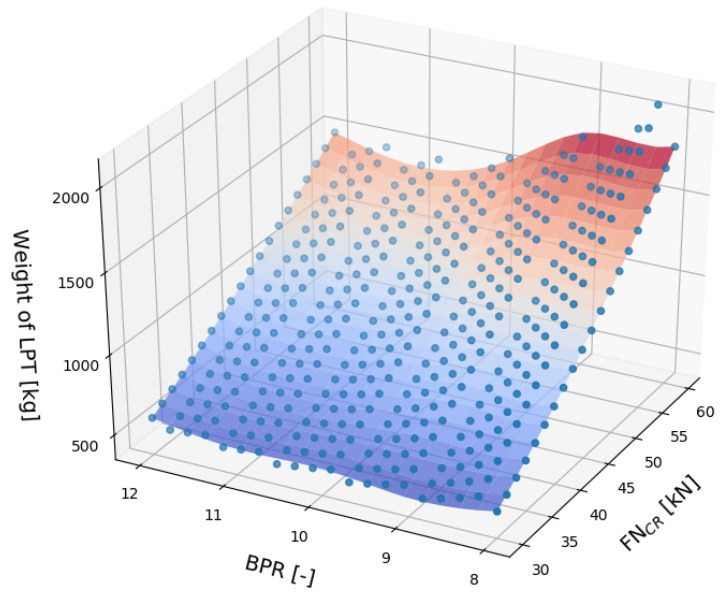

(a) LPT weight as a function of $\mathrm{BPR}$ and $\mathrm{FN}_{\mathrm{CR}}$

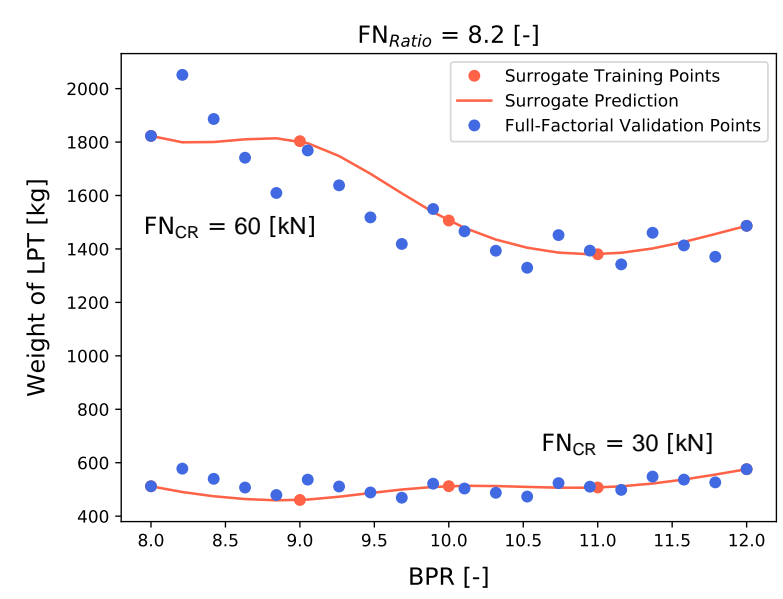

(b) LPT weight as a function of BPR for selected values of $\mathrm{FN}_{\mathrm{CR}}$

Fig. 17 LPT weight of additional validation engines and the rubber engine model prediction as a function of $B P R$ and $F N_{C R}$ for $F N_{\text {Ratio }}=$ 8.2. The rubber engine model is build based on a full-factorial DoE with 125 samples and cubic interpolation. 
The validation points and the predictions are shown in Fig. $17 \mathrm{a}$ as a function of BPR and $\mathrm{FN}$ CR for a constant $\mathrm{FN}_{\text {Ratio }}$. The LPT gets significantly heavier with increasing CR thrust due to higher mass flows through the core and hence larger dimensions. In contrast, the LPT weight varies only slightly with BPR. A nearly constant level is maintained for $\mathrm{FN}_{\mathrm{CR}}=30 \mathrm{kN}$ and the trend of the LPT weight for $\mathrm{FN}_{\mathrm{CR}}=60 \mathrm{kN}$ initially shows a decrease, remains nearly constant around BPR $=11$ and then slightly raises (see Fig. 17b). In both cases at several positions a discontinuous increase in the weight of the LPT is induced by discrete changes in the number of stages. The weight decreases in the sections between transitions in the stage number. This is attributed to a reduction of the rotational speed due to larger fan diameters and hence lighter LPT disks. The rubber engine model can not predict the discontinuous changes in weight correctly because these are not resolved by the training samples. For this reason the accuracy for predicting the weight, the length and the center of gravity is limited to the levels shown in Tab. 8 and 9 unless the discontinuous transitions are resolved by an enormous amount of training points. In the case of the component-based procedure, the accuracy in bare engine weight is worse compared to the part-based approach, since the predicted LPT weight has a larger share of the total engine weight (see Tab. 6). Furthermore, the sensitivities produced by the weight surrogate model strongly depend on the more or less random position of the training points in between the discontinuous transitions. As a consequence, the mean trend of engine parameters is not necessarily predicted correctly by means of the rubber engine model, as it is the case for the LPT weight with BPR $=9$ and $\mathrm{FN}_{\mathrm{CR}}=60 \mathrm{kN}$ in Fig. $17 \mathrm{~b}$.

\section{Conclusion and Outlook}

A hybrid surrogate-based rubber engine model that combines surrogate models for various engine parameters and a tool for thermodynamic cycle analysis was presented. This concept enables the optimal choice of engine design variables in terms of the overall system performance as well as the matching of requirements during an aircraft MDO. By means of the proposed hybrid approach not only the engine dimensions, weight and center of gravity can be provided but also the detailed operational performance for any operating point of the flight mission.

A conceptual engine design methodology including the disciplines thermodynamics, geometry and weight was described in detail. On the basis of this methodology, a generic 3-spool unmixed turbofan engine model was created and calibrated against available data on the Trent 1000 engine. A complete set of requirements for the operating conditions $\mathrm{CR}$, TOC and MTO was provided and trading factors were calculated to evaluate changes of the engine fuel consumption and weight at the level of block fuel. The thermodynamic cycle of the engine model, the created geometry and a detailed breakdown of weight estimation results using a component-based and a part-based approach were presented. The main engine design variables BPR, OPR, $T_{4}$ as well as the thrust at CR and MTO conditions were varied within parameter studies and the design space of the rubber engine model was explored. It was found that the engine design methodology leads to physically reasonable trends and geometries with smooth flow paths. Trade studies were performed at the block fuel level to discuss the optimal selection of engine design variables that will not be covered by the rubber engine model. It was concluded that the OPR and $T_{4}$ at $\mathrm{CR}$ should be selected to reach the maximum permissible temperature limits at MTO.

A three-dimensional parameter space given by the BPR, the thrust at CR and the ratio of MTO to CR thrust was considered for the creation of rubber engine models. Various combinations of DoE methods, several interpolation and regression approaches and a varying number of samples were combined. The accuracy of the created models was assessed by means of a validation sampling taking into account mean and maximum relative deviations of thermodynamic parameters, the engine radius, length, weight and center of gravity.

It was found that either cubic interpolation or Kriging regression models combined with a full-factorial sampling with 64 or more training points should be selected to build an efficient rubber engine model for the investigated parameter space. This allows predictions of the thermodynamic parameters with a maximum relative error less than $0.5 \%$, of the bare engine weight with a maximum relative deviation less than $4 \%$ and in the case of the engine length and center of gravity with less than $2 \%$. Changes in integer-numbered engine parameters like the LPT stage number, which lead to discontinuous increases in length, weight and hence center of gravity, were identified as challenging if the accuracy of the rubber engine model should be further improved.

For future work it might be of interest to create rubber engine models that account for discontinuous changes of engine parameters without increasing the number of training samples tremendously. In addition, an extension of the rubber engine parameter space, e.g. by the flight Mach number or altitude at CR, could be beneficial for the application in the MDO context. Furthermore, it is planned to integrate a hybrid surrogate-based rubber engine model into an aircraft MDO process taking into account complex snowball effects. 


\section{References}

[1] Abu-Zurayk, M., “An Aeroelastic Coupled Adjoint Approach for Multi-Point Designs in Viscous Flows.” Tech. rep., 2017.

[2] Blondeau, C., Achard, T., Girodroux-Lavigne, P., and Ohayon, R., "Recent Achievements towards Aero-Structure Gradient Computation using High-Fidelity CFD-CSM in the ONERA elsA Software.” IFASD Conference, Saint Peterburg, Russia, 2015.

[3] Zhang, Z., and Zingg, D., "Efficient Monolithic Solution Algorithm for High-Fidelity Aerostructural Analysis and Optimization." AIAA Journal, Vol. 56, No. 3, 2017, pp. 1251-1265.

[4] Kenway, G., Kennedy, G., and Martins, J., "Scalable Parallel Approach for High-Fidelity Steady-State Aeroelastic Analysis and Adjoint Derivative Computations.” AIAA Journal, Vol. 52, No. 5, 2014, pp. 935-951.

[5] Merle, A., Ilic, C., Abu-Zurayk, M., Häßy, J., Becker, R., Schulze, M., and Klimmek, T., "High-Fidelity Adjoint-based Aircraft Shape Optimization with Aeroelastic Trimming and Engine Coupling,” EUROGEN Conference, Guimaraes, Portugal, 2019.

[6] Gray, J., and Martins, J., “Coupled Aeropropulsive Design Optimization of a Boundary Layer Ingestion Propulsor.” Aeronautical Journal, Vol. 123, No. 1259, 2019, pp. 121-137.

[7] Heath, C., Seidel, J., and Rallabhandi, S. K., "Viscous Aerodynamic Shape Optimization with Installed Propulsion Effects," 35th AIAA Applied Aerodynamics Conference, Denver, CO, USA, 2017.

[8] Raymer, D. P., Aircraft Design: A Conceptual Approach, American Institute of Aeronautics and Astronautics, Inc., Washington, DC, 1992. ISBN 0-930403-51-7.

[9] Drela, M., "Simultaneous optimization of the airframe, powerplant, and operation of transport aircraft," Hamilton Place, London, 2010.

[10] Pantalone, G. B., et al., "Development of an engine model for an integrated aircraft design tool," Ph.D. thesis, Massachusetts Institute of Technology, 2015.

[11] Greitzer, E., Bonnefoy, P., DelaRosaBlanco, E., Dorbian, C., Drela, M., Hall, D., Hansman, R., Hileman, J., Liebeck, R., Lovegren, J., et al., "N+3 aircraft concept designs and trade studies. volume 2; appendices-design methodologies for aerodynamics, structures, weight, and thermodynamic cycles," 2010.

[12] Kupijai, P., "Ein Beitrag zur automatisierten Triebwerksvorauslegung," Ph.D. thesis, Technische Universität Cottbus, Cottbus, Germany, 2014.

[13] Lammen, W., Kupijai, P., Kickenweitz, D., and Laudan, T., "Integrate engine manufacturer's knowledge into the preliminary aircraft sizing process," Aircraft Engineering and Aerospace Technology: An International Journal, 2014.

[14] Reitenbach, S., Krumme, A., Behrendt, T., Schnös, M., Schmidt, T., Hönig, S., Mischke, R., and Mörland, E., "Design and Application of a Multidisciplinary Predesign Process for Novel Engine Concepts," Journal of Engineering for Gas Turbines and Power, Vol. 141, No. 1, 2019.

[15] Reitenbach, S., Becker, R., Hollmann, C., Wolters, F., Vieweg, M., Schmeink, J., Otten, T., and Siggel, M., "Collaborative Aircraft Engine Preliminary Design using a Virtual Engine Platform, Part A: Architecture and Methodology," AIAA SciTech Forum, 2020.

[16] Becker, R. G., Reitenbach, S., Klein, C., Otten, T., Nauroz, M., and Siggel, M., "An Integrated Method for Propulsion System Conceptual Design," Proceedings of ASME Turbo Expo 2015: Turbine Technical Conference and Exposition, 2015. ASME Paper No. GT2015-43251.

[17] Han, Z.-H., and Görtz, S., "Hierarchical Kriging Model for Variable-Fidelity Surrogate Modeling," AIAA Journal, Vol. 50, 2012, pp. 1885-1896. https://doi.org/10.2514/1.J051354.

[18] Franz, T., Zimmermann, R., Görtz, S., and Karcher, N., "Interpolation-based Reduced-order Modeling for Steady Transonic Flows via Manifold Learning," Special Issue: Reduced order modelling: the road towards real-time simulation of complex physics, International Journal of Computational Fluid Dynamics, Vol. 28, No. 3-4, 2014, pp. 106-121.

[19] Ripepi, M., Verveld, M., Karcher, N., Franz, T., Abu-Zurayk, M., Görtz, S., and Kier, T., "Reduced Order Models for Aerodynamic Applications, Loads and MDO,” CEAS Aeronautical Journal, Vol. 9, No. 1, 2018, pp. 171-193.

[20] Bretschneider, S., Knowledge-based preliminary design of aero-engine gas-generators, Dissertation. de, 2011.

[21] EASA, “Type-Certificate Data Sheet for Trent 1000 series engines,” Tech. Rep. TCDS No. E.036, EASA, April 2019. 
[22] ICAO, "ICAO Engine Exhause Emissions Data Bank," https://www.easa.europa.eu 2019. Accessed: 2019-10-01.

[23] Daly, M., Jane’s Aero-Engines, Jane’s IHS Markit, 2019. ISBN 978-0-7106-3310-1.

[24] Grieb, H., Projektierung von Turboflugtriebwerken, Birkhäuser Verlag, Basel, Switzerland, 2004. ISBN 978-3-0348-7938-5.

[25] Lupelli, L., “A Study Integration IP Power Offtake System within Trent 1000 Turbofan Engine,” Rolls-Royce plc, 2011.

[26] EASA, “Type-Certificate Data Sheet for BOEING 787,” Tech. Rep. TCDS No. EASA.IM.A.115, EASA, October 2019.

[27] Xiao, C., Xiongqing, Y., and Yu, W., "Multipoint optimization on fuel efficiency in conceptual design of wide-body aircraft," Chinese Journal of Aeronautics, Vol. 31, No. 1, 2018, pp. 99-106.

[28] Walsh, P. P., and Fletcher, P., Gas turbine performance, John Wiley \& Sons, 2004.

[29] Häßy, J., and Schmeink, J., "Knowledge-Based Conceptual Design Methods for Geometry and Weight Estimation of Rubber Aero Engines,", 2020. In preparation.

[30] Sagerser, D. A., Lieblein, S., and Krebs, R. P., "Empirical Expressions for Estimating Length and Weight of Axial-Flow Components of VTOL Powerplants,” Tech. Rep. No. NASA TM X-2406, NASA Lewis Research Center, Cleveland, OH, USA, 1971.

[31] Pera, R., Onat, E., Klees, G., and Tjonneland, E., "A method to estimate weight and dimensions of aircraft gas turbine engines. Volume 1: Method of analysis," 1977.

[32] Klees, G., and Fishbach, L., Aircraft Engine Weight Estimating Method: For Presentation at the Thirty-seventh Annual Conference of the Society of Allied Weight Engineers Inc., Munich, West Germany May 1978, Society of Allied Weight Engineers, 1978. 